\title{
One-dimensional model of a closed low-pressure adsorber for thermal energy storage
}

\author{
M. Schaefer ${ }^{\mathrm{a}, *}$, A. Thess ${ }^{\mathrm{a}, \mathrm{b}}$ \\ ${ }^{a}$ Institute of Energy Storage, University of Stuttgart, Pfaffenwaldring 31, 70569 Stuttgart, Germany \\ ${ }^{b}$ Institute of Engineering Thermodynamics, DLR - German Aerospace Center, Pfaffenwaldring 38-40, 70569 Stuttgart, Germany
}

\begin{abstract}
The energy transition from fossil to renewable energy requires the development and integration of efficient energy storages. For thermal energy storage, concepts based on adsorption are promising. One key challenge is to overcome limitations of the storage performance by the heat and mass transfer. Against this background, a closed low-pressure adsorber with zeolite $13 \mathrm{X}$ honeycomb adsorbent is studied numerically to identify the limiting factors. The focus of the study is on the adsorption process with the heat extraction limited to the end of the zeolite honeycomb arrangement. A detailed model which takes effects of rarefied gas flow (e. g. slip) as well as cooling effects by the inflowing vapour into account is derived. The model is applied to study the mass transport, heat transport and adsorption over a broad range of relevant geometry and process parameters. The simulations demonstrate that the adsorption process is not limited by the mass transport and isobaric conditions can be assumed in most of the studied cases. In addition, special effects of rarefied gas flow are found to be negligible. Regarding the heat transport, the convective cooling by the vapour is found only to be significant for a very short initial time period. Further analysis show that the process is mainly limited by the heat transport. Only for short channels and wide channel diameters the process becomes limited by the adsorption.
\end{abstract}

Keywords:

Adsorption, Zeolite, Honeycomb, Vacuum, Thermal Energy Storage, Simulation

\section{Introduction}

\subsection{Motivation and Subject Matter}

The energy transition from fossil to renewable energy requires the development and integration of efficient energy storages. Energy storages are required for both electrical and thermal energy. For thermal energy storage (TES) the thermochemical energy storages (TCES) offer several specific advantages. The main advantages are: high energy density, high efficiency, negligible long-term losses and the possibility to utilize the TCES as a heat pump or transformer [1]. A broad definition of TCES also includes TES based on adsorption. One key challenge is to overcome limitations of the storage performance (e. g. discharging power and temperature) by the heat and mass transfer [2]. Against this background, a closed low-pressure adsorber system with zeolite is studied numerically to identify the limiting factors. Closed low-pressure adsorber systems are of particular interest for seasonal storage of solar energy [3] as well as for domestic heat pump systems [4] but are also studied for industrial application [5].

The scheme and storage principle of the examined closed adsorption system is shown in Fig. 1. The system consists of the two main vessels: adsorber and water vessel. In accordance with applied research in the field (e.g. [6, 7]), zeolite 13X and water are assumed as working materials. Both vessels are connected vacuum-tight via a pipe and are initially evacuated. Dur-

\footnotetext{
${ }^{*}$ Corresponding author

Email address: schaefer@ies. uni-stuttgart.de (M. Schaefer)
}

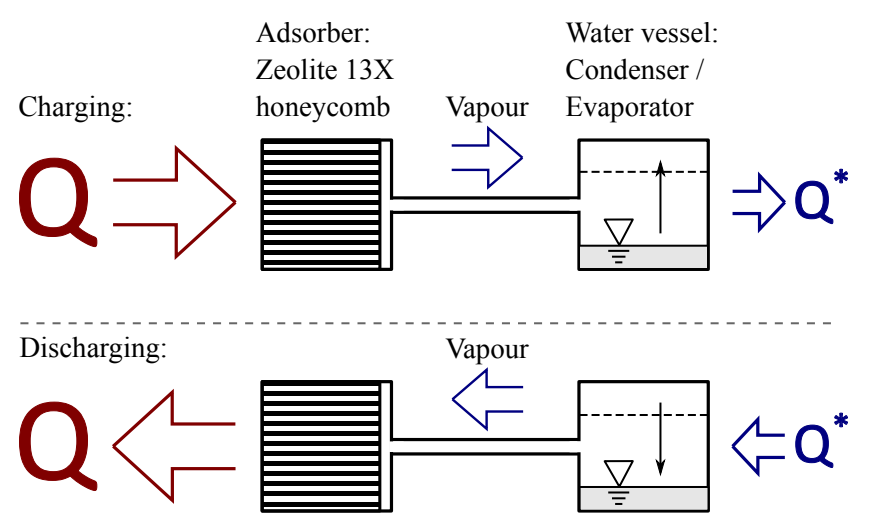

Figure 1: Scheme and storage principle of the closed adsorption system.

ing the charging process the adsorbed water in the zeolite is desorbed by a high-temperature heat input $Q$. At the same time the arising vapour is being condensed in the water vessel while releasing the heat of condensation $Q^{*}$ at a low-temperature level. Over the storing period the two vessels are simply separated by a valve. During the discharging process the charging process is reversed by evaporating the water in the water vessel by a low-temperature heat input $Q^{*}$. The vapour is then adsorbed by the zeolite while releasing the heat of adsorption $Q$ at a hightemperature level. With the focus on seasonal storage of solar energy, typical operating temperatures of the water vessel are in the range of $T_{\mathrm{wvl}} \approx 5 \ldots 25^{\circ} \mathrm{C}$. Hence, the vapour pressure in the water vessel is in the range of $p_{\mathrm{wvl}} \approx 8 \ldots 32$ mbar, defining the in- and outlet pressure of the adsorber. 


\begin{tabular}{|c|c|c|c|}
\hline \multicolumn{4}{|c|}{ Nomenclature } \\
\hline & & $u$ & mean vapour velocity in zeolite channel $(\mathrm{m} / \mathrm{s})$ \\
\hline$A$ & cross-section area $\left(\mathrm{m}^{2}\right)$ & $u_{\text {slip }}$ & slip velocity of vapour at channel wall (m/s) \\
\hline$c$ & specific heat capacity at constant volume (J/kg K) & $v$ & specific volume $\left(\mathrm{m}^{3} / \mathrm{kg}\right)$ \\
\hline$c_{p}$ & specific heat capacity at constant pressure $(\mathrm{J} / \mathrm{kg} \mathrm{K})$ & $\mathrm{d} V$ & infinitesimal control volume $\left(\mathrm{m}^{3}\right)$ \\
\hline$d_{\mathrm{i}}$ & inner/channel diameter of zeolite cut-out (m) & $X$ & water uptake of zeolite $(\mathrm{kg} / \mathrm{kg})$ \\
\hline$d_{\mathrm{mp}}$ & mean macro pore diameter of zeolite $(\mathrm{m})$ & $X_{\mathrm{eq}}$ & adsorption equilibrium of zeolite $(\mathrm{kg} / \mathrm{kg})$ \\
\hline$d_{\mathrm{o}}$ & outer diameter of zeolite cut-out (m) & $z$ & axial coordinate of zeolite cut-out $(\mathrm{m})$ \\
\hline$D_{\text {eff }}$ & effective diffusivity of water uptake in zeolite $\left(\mathrm{m}^{2} / \mathrm{s}\right)$ & \multicolumn{2}{|c|}{ Greek symbols } \\
\hline$D_{K n}$ & Knudsen diffusivity of vapour in zeolite $\left(\mathrm{m}^{2} / \mathrm{s}\right)$ & $\alpha_{1}, \alpha_{2}$ & fitting parameters of specific heat of adsorbate \\
\hline$e$ & specific internal energy $(\mathrm{J} / \mathrm{kg})$ & & coefficient of thermal expansion of adsorbate $\left(\mathrm{K}^{-1}\right)$ \\
\hline E & char. energy in Dubinin-Astakhov equation $(\mathrm{J} / \mathrm{kg})$ & $\gamma$ & diameter ratio of zeolite cut-out $(\mathrm{m} / \mathrm{m})$ \\
\hline$G_{\mathrm{P}}$ & Poiseuille coefficient $(-)$ & $\delta$ & local rarefaction parameter $(-)$ \\
\hline$h$ & specific enthalpy $(\mathrm{J} / \mathrm{kg})$ & $\varepsilon$ & inner porosity of zeolite $\left(\mathrm{m}^{3} / \mathrm{m}^{3}\right)$ \\
\hline$\Delta h_{\mathrm{a}}$ & heat of adsorption $(\mathrm{J} / \mathrm{kg})$ & $\lambda$ & heat conductivity $(\mathrm{W} / \mathrm{m} \mathrm{K})$ \\
\hline$\Delta h_{\mathrm{e}}$ & heat of evaporation $(\mathrm{J} / \mathrm{kg})$ & $\lambda_{\mathrm{eff}}$ & effective heat conductivity (W/m K) \\
\hline$k_{\mathrm{a}}$ & adsorption kinetics parameter $\left(\mathrm{s}^{-1}\right)$ & & dynamic viscosity (Pas) \\
\hline Kn & Knudsen number $(-)$ & & density $\left(\mathrm{kg} / \mathrm{m}^{3}\right)$ \\
\hline$l_{\mathrm{mol}}$ & mean free path of vapour molecules $(\mathrm{m})$ & & mean tortuosity of zeolite $(-)$ \\
\hline & channel length of zeolite cut-out (m) & \multicolumn{2}{|c|}{ Subscripts } \\
\hline $\mathrm{d} \dot{m}$ & infinitesimal mass flow rate $(\mathrm{kg} / \mathrm{s})$ & 0 & initial state \\
\hline $\begin{array}{l}n \\
p\end{array}$ & $\begin{array}{l}\text { heterogeneity parameter in Dub.-Ast. eq. (-) } \\
\text { vapour pressure (Pa, mbar) }\end{array}$ & $\mathrm{a}$ & adsorbate, adsorption \\
\hline$\dot{q}$ & heat flux $\left(\mathrm{W} / \mathrm{m}^{2}\right)$ & $\mathrm{c}$ & channel \\
\hline$Q$ & heat input/output of adsorber (W) & in & inlet of adsorber \\
\hline$Q^{*}$ & heat input/output of water vessel (W) & $\max$ & maximum \\
\hline & radial coordinate of zeolite cut-out (m) & $\min$ & minimum \\
\hline$R_{\mathrm{S}}$ & specific gas constant of vapour $(\mathrm{J} / \mathrm{kg} \mathrm{K})$ & ref & reference state \\
\hline$s$ & fitting parameter of dynamic viscosity (-) & $\mathrm{s}$ & saturation state \\
\hline$t$ & time $(\mathrm{s})$ & $\mathrm{v}$ & vapour \\
\hline & non-dimensional time $\tilde{t}:=t / t_{\text {tot }}(-)$ & wvl & water vessel \\
\hline & total process duration $(\mathrm{s})$ & $\mathrm{z}$ & zeolite \\
\hline$t_{p, 99}$ & relative time for $p(L, \widetilde{t})=0.99 p(0)(\mathrm{s})$ & \multicolumn{2}{|c|}{ Abbreviations } \\
\hline & temperature $\left(\mathrm{K},{ }^{\circ} \mathrm{C}\right)$ & TCES & thermochemical energy storage \\
\hline$T_{\mathrm{htx}}$ & temperature of heat exchanger $(\mathrm{K})$ & TES & thermal energy storage \\
\hline
\end{tabular}

Most publications regarding modelling and simulation of closed low-pressure adsorbers assume a packed-bed adsorber filled with spherical adsorbent particles [8,9] or adsorbers with coated heat exchanger tubes [4]. In contrast, an adsorber with structured zeolite honeycombs is examined in this study to analyse possible limitations of the storage performance by the heat and mass transfer. The particular advantage of this adsorber system is its geometric simplicity which allows a straightforward derivation of the conceptual mathematical model. The manufacturing process of zeolite honeycombs for TES application has been presented in [10]. Fig. 2 shows different manufactured zeolite honeycombs with variation of the channel width and web thickness. Typical channel widths vary around $1 \mathrm{~mm}$ with a web thickness in the range of $0.2 \ldots 2 \mathrm{~mm}$.

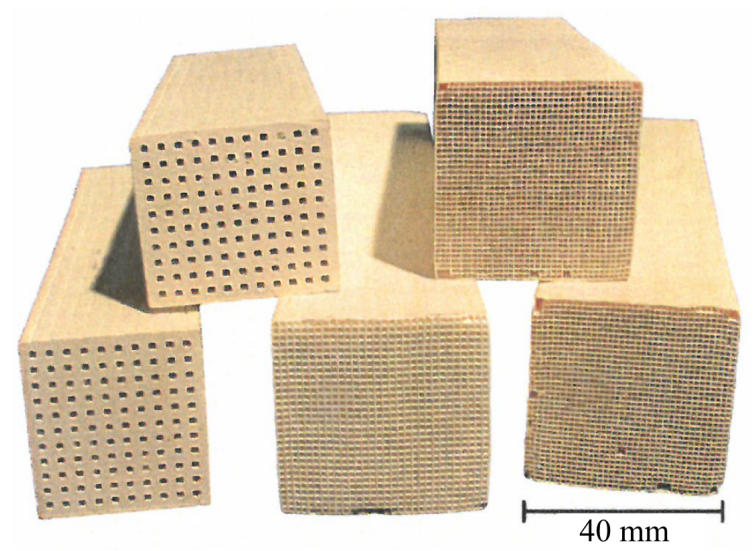

Figure 2: Different zeolite honeycombs with variation of the channel diameter and web thickness, courtesy of Benjamino R. Formisano. 


\subsection{Literature Review}

Many of the publications regarding honeycomb adsorbents focus on the manufacturing process and the experimental examination, e.g. $[11,12,13]$. The field of application often covers catalysis or gas separation. The usage of honeycomb adsorbers for TES application in open adsorption systems is discussed in $[10,14,15]$. Besides the description of the manufacturing process, performance aspects such as pressure drop, heat transfer, adsorption kinetics and capacity are discussed only qualitatively or by simple models.

Regarding the detailed modelling and simulation of zeolite honeycomb adsorbers our literature research found relatively few publications [14, 16, 17]. The publications have in common, that they all examine open adsorption systems while assuming a stationary flow of the carrier gas. In [16] a detailed 3D model as well as a simplified 1D model are presented, but the simulations are limited to the adsorption of propane and propylene on zeolite 4A. The adsorption of water vapour on zeolite $4 \mathrm{~A}$ is analysed numerically and experimentally in [14]. The focus is on the comparison of the water vapour desorption from spherical zeolite particles and from zeolite honeycombs. Unfortunately, the mathematical model is not described in detail. In comparison, our work provides a conceptually simple but detailed model to analyse the heat and mass transfer in closed low-pressure adsorption systems with zeolite honeycomb adsorbers.

In contrast to the before mentioned modelling approaches, many publications exist for the modelling and simulation of closed low-pressure adsorption systems with packed-bed adsorbers of spherical zeolite particles(grain and powder) and adsorbers with zeolite coated heat exchanger tubes. A detailed review of different modelling approaches for such closed adsorption systems is given in [8], [9] and [4]. More recent publications which are not included in the cited review articles are e. g. [18, 19]. In general, the modelling can be categorized in three groups: mass transport, heat transport and adsorption. Furthermore, the modelling approaches can be distinguished by their complexity regarding the spatial dimension, consideration of physical effects and the level or scale of the model. In comparison to our approach, most of the modelling approaches have in common, that special effects of rarefied gas flow, such as the slip-effect, are not considered.

\subsection{Objectives of Study}

According to [2] the heat and mass transfer in the adsorber, both for open and closed adsorption systems, remain the limiting factors for the system performance. As noted in the literature review the focus of research so far is either on open adsorption systems or, in the case of closed adsorption systems, is limited to packed-bed adsorbers with spherical zeolite particles or zeolite coated tubes. Thus, the main objective of this work is to provide a conceptual model that enables to study the heat and mass transfer / transport for closed adsorption systems with honeycomb adsorbents. The developed model is then applied to identify the limiting factors for a specific adsorber set-up over a wide range of set-up parameters. The study is limited to the working materials zeolite $13 \mathrm{X}$ and water.
More specifically, the following questions regarding the mass transport, heat transport and adsorption are analysed:

Mass Transport:

- Is it valid to assume isobaric conditions or is the mass transport of the water vapour relevant?

- Is the Darcy's law applicable or is it necessary to take specific effects of rarefied gas flow into account?

Heat Transport:

- Is convective cooling by the vapour negligible?

- Which parameters determine the maximum temperature reached in the adsorber during adsorption?

Adsorption:

- Is the assumption of local adsorption equilibrium valid or are limitations by the adsorption kinetics relevant?

Since the adsorption process in general shows a higher dynamic than the desorption process, the simulations are limited to the adsorption process to answer these questions. Similar analysis have been presented in $[9,20]$ to discuss possible limitations by the mass transport in closed adsorption systems with packedbed adsorbers.

At last, different authors come to different conclusions regarding the specific questions above. One reason is, that different adsorber set-ups with different geometrical and material parameters as well as operating conditions are studied. Following from that, simulations are carried out over a broad range of relevant geometry and process parameters in this study.

The paper is organized as follows: The description of the conceptual model is given in Sect. 2. Following, the numerical implementation is briefly presented in Sect. 3 before the results are discussed in Sect. 4.

\section{Model Description}

\subsection{Modelling Approach}

The examined closed low-pressure adsorber system is shown in Fig. 3. During the adsorption process, vapour from the water vessel is flowing into the adsorber by the vapour inlet. It is assumed, that the pressure in the water vessel $p_{\mathrm{wvl}}$ is not effected by the adsorption process (no evaporator limitations) and is constant throughout the adsorption process. Thus, the adsorber inlet pressure is constant $p_{\text {in }}=p_{\mathrm{wvl}}$. In addition, the temperature of the vapour at the inlet is assumed to be equal to the saturation temperature $T_{\mathrm{in}}=T_{\mathrm{s}}\left(p_{\mathrm{wvl}}\right)$. Furthermore, it is assumed that the inflowing vapour distributes homogeneously into the void space over the zeolite honeycomb arrangement inside the adsorber. The zeolite honeycomb arrangement is characterized by a uniform channel width and web thickness. Regarding the thermal insulation of the adsorber, ideal insulation is being assumed. Heat extraction is realized by the heat exchanger at the closed end of the zeolite honeycomb arrangement. It is assumed that the heat exchanger leads to an uniform and constant 


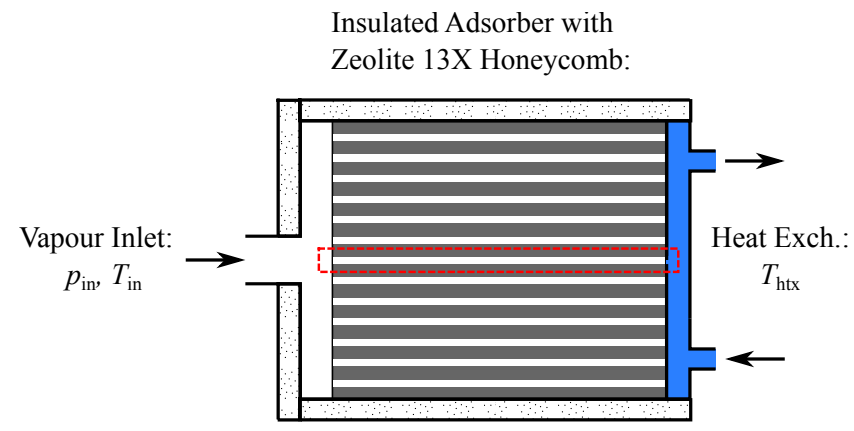

Figure 3: Examined closed low-pressure adsorber system. The dashed red box marks a single cut out zeolite channel for the formulation of the onedimensional model.

temperature $T_{\mathrm{htx}}$ at the closed end of the zeolite honeycomb arrangement. Hence, temperature gradient and thus heat transport only exists in direction of the zeolite honeycomb channels towards the heat exchanger.

Following from the description above, it can be concluded that the heat and mass transport / transfer processes in the single channels are identical for the examined adsorber system, since no heat and mass transfer occurs between the channels. Thus, the analysis of a single channel from the zeolite honeycomb arrangement is sufficient. The cut out zeolite channel marked in Fig. 3 (dashed red box) is shown in Fig. 4. For simplification and dimensions reduction, the usually rectangular channel and zeolite cut-out is transformed to an axially symmetric geometry (circular pipe). The required transformation equations can be found in [17]. The thickness of the cut out zeolite corresponds to half of the web thickness of the zeolite honeycomb. Here it should be noted already, that, while the following derived model is mathematically one-dimensional, it implicitly includes two-dimensional aspects. One two-dimensional aspect results from the parabolic velocity profile of the vapour in the channel. Another two-dimensional aspect follows from the adsorption model which assumes a radially parabolic pressure and water uptake profile. At last, the transformation to a mathematically one-dimensional model reduces the computational time significantly. Hence, parameter studies over a broad and relevant range can be conducted in a reasonable time.

As discussed, heat transport only takes place in the direction of the zeolite channel. Hence, adiabatic boundary conditions are applied at the circumference of the zeolite cut-out. Only at the end of the channel a fixed temperature boundary condition

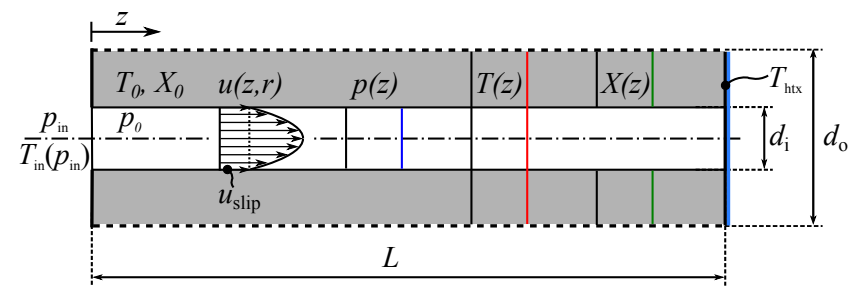

Figure 4: Single cut out zeolite channel with adiabatic boundary conditions at the circumference for the formulation of the one-dimensional model. For simplification, the cut-out is transformed to a circular pipe. is applied to model the heat extraction by the heat exchanger. Regarding the pressure, a constant pressure is set at the inlet. Since the mass flow rate and thus the vapour velocity at the closed end of the channel are zero, no pressure gradient exists at the closed end, see Eq. (6). Note that no boundary conditions are required for the water uptake, since the axial mass transport in the zeolite itself is negligible compared to the mass transport by the channel flow. The final boundary conditions applied, are

$$
p(0, t)=p_{\mathrm{in}},\left.\frac{\partial p}{\partial z}\right|_{z=L}=0,\left.\frac{\partial T}{\partial z}\right|_{z=0}=0, T(L, t)=T_{\mathrm{htx}} .
$$

The initial conditions are chosen according to a typical operating case of a closed adsorption system for seasonal storage of solar energy. During thermal (pre-)discharging of the adsorber the vapour inlet is usually kept closed as long as the extraction of the sensible heat is sufficient. The decreasing temperature in the adsorber leads to a re-adsorption of the remaining vapour in the zeolite channels resulting in very low initial pressures of $p_{0} \leq 0.1$ mbar. This indicates, that special effects of rarefied gas flow, such as the slip-effect, might be relevant for the mass transport. Assuming equilibrium for the initial adsorber state the initial conditions are

$$
p(z, 0)=p_{0}, T(z, 0)=T_{0}, X(z, 0)=X_{\text {eq }}\left(p_{0}, T_{0}\right),
$$

with the water uptake being defined as $X(z, t):=m_{\mathrm{a}} / m_{\mathrm{z}}$, where $m_{\mathrm{a}}$ and $m_{\mathrm{z}}$ denote the mass of the adsorbate and the pure zeolite.

In summary, given the boundary conditions (1) as well as the initial conditions (2) the three dependent variables vapour pressure $p(z, t)$, temperature $T(z, t)$ and water uptake $X(z, t)$ are computed.

\subsection{Modelling Equations}

\subsubsection{Mass Transport}

To derive the mass transport equation the continuity equation of the vapour in the channel is required

$$
\frac{\partial \rho_{\mathrm{v}}}{\partial t}+\frac{\partial}{\partial z}\left(\rho_{\mathrm{v}} u\right)=-\frac{\mathrm{d} \dot{m}_{\mathrm{c}, \mathrm{z}}}{\mathrm{d} V}
$$

where $\rho_{\mathrm{v}}$ denotes the vapour density, $u$ the mean vapour velocity in $z$-direction over the channel cross-section and $\mathrm{d} \dot{m}_{\mathrm{c}, \mathrm{z}} / \mathrm{d} V$ the volumetric mass flow rate of the vapour from the channel into the zeolite.

Due to the low vapour pressure the ideal gas law

$$
\rho_{\mathrm{v}}=\frac{p}{R_{\mathrm{s}} T}
$$

can be applied, where $R_{\mathrm{s}}$ denotes the specific gas constant of the vapour. Further, the vapour is assumed as a Newton-fluid with the dynamic viscosity $\mu$ calculated from

$$
\mu=\mu_{\text {ref }}\left(\frac{T}{T_{\text {ref }}}\right)^{s}
$$

where $\mu_{\text {ref }}$ denotes the reference viscosity at the reference temperature $T_{\text {ref }}$ and the exponent $s$ the fitting parameter to fit the curve to tabulated vapour viscosity from [21]. 
Considering the relatively small channel diameter, creeping flow can be assumed. Further, it is assumed that the change of velocity in axial direction is negligible compared to the radial dependency of the velocity. Finally applying the common no-slip boundary condition yields

$$
u=-\frac{d_{\mathrm{i}}^{2}}{32} \frac{1}{\mu} \frac{\partial p}{\partial z}
$$

where $d_{\mathrm{i}}$ denotes the channel diameter. The result can also be obtained by locally applying the Poiseuille equation for incompressible channel flow and corresponds to the often applied Darcy's law for flow through porous media.

Specific effects of rarefied gas flow are not taken into account by Eq. (6). The type and corresponding effects of a rarefied gas flow are characterised by the non-dimensional Knudsen number

$$
K n:=\frac{l_{\mathrm{mol}}}{d_{\mathrm{i}} / 2}=\frac{\mu}{d_{\mathrm{i}} / 2} \frac{l_{\mathrm{mol}}}{\mu} \approx \sqrt{\frac{\pi}{2}} \frac{2 \mu}{d_{\mathrm{i}}} \frac{\sqrt{R_{\mathrm{s}} T}}{p}
$$

where $l_{\text {mol }}$ denotes the mean free path of the vapour molecules [22]. For $K n \geq 0.01$ the slip-effect becomes relevant and a slip velocity should be considered instead of the no-slip boundary condition. In the transition range of $0.1 \leq K n \leq 10$ the flow type changes from continuum flow to free molecular flow, yielding a homogeneous velocity profile over the channel cross section. This effect leads to significantly higher mass flow rates in this flow regime compared to the mass flow rates calculated under the usual assumption of a parabolic velocity profile.

A more general equation taking the described effects of rarefied gas flow into account is given by

$$
u=-\frac{d_{\mathrm{i}}^{2}}{32} \frac{1}{\mu} \frac{4}{\delta} G_{\mathrm{P}}(\delta) \frac{\partial p}{\partial z}
$$

where $\delta$ denotes the local rarefaction parameter and $G_{\mathrm{P}}$ the socalled Poiseuille coefficient [23]. With the definition in Eq. (7) the rarefaction parameter is related to the Knudsen number by

$$
\delta=\frac{\sqrt{\pi}}{2} \frac{1}{K n}
$$

while the Poiseuille coefficient can be calculated from

$$
\begin{aligned}
G_{\mathrm{P}}=\frac{1.505+0.0524 \delta^{0.75} \ln (\delta)}{1+0.738 \delta^{0.78}}+ \\
\left(\frac{\delta}{4}+1.018\right) \frac{\delta}{1.0738+\delta} .
\end{aligned}
$$

For small values of the Knudsen number $(K n \rightarrow 0, \delta \rightarrow \infty)$, Eq. (8) takes the form of Eq. (6).

The volumetric mass flow rate $\mathrm{d} \dot{m}_{\mathrm{c}, \mathrm{z}} / \mathrm{d} V$ of the vapour from the channel into the zeolite is discussed in Sect. 2.2.3 and is given by Eq. (27).

\subsubsection{Heat Transport}

Under the assumption of locally ideal heat transfer between the zeolite, adsorbate and vapour it is sufficient to formulate one common energy balance equation for the zeolite, adsorbate and vapour

$$
\begin{aligned}
\frac{\partial}{\partial t}\left(\rho_{\mathrm{z}} e_{\mathrm{z}}+\rho_{\mathrm{z}} X e_{\mathrm{a}}+\left(\frac{A_{\mathrm{c}}}{A_{\mathrm{z}}} \rho_{\mathrm{v}}+\varepsilon(\right.\right. & \left.\left.(X) \bar{\rho}_{\mathrm{v}, \mathrm{z}}\right) e_{\mathrm{v}}\right)= \\
& -\frac{\partial \dot{q}}{\partial z}-\frac{\partial}{\partial z}\left(\frac{A_{\mathrm{c}}}{A_{\mathrm{z}}} \rho_{\mathrm{v}} u h_{\mathrm{v}}\right),
\end{aligned}
$$

where $\rho_{\mathrm{z}}$ and $\bar{\rho}_{\mathrm{v}, \mathrm{Z}}$ denote the density of the zeolite and the mean density of the vapour in the zeolite. The variables $e_{\mathrm{z}}, e_{\mathrm{a}}$ and $e_{\mathrm{v}}$ correspond to the specific internal energy of the zeolite, the adsorbate and the vapour. The cross-section area of the channel and of the zeolite are given by $A_{\mathrm{c}}$ and $A_{\mathrm{z}}$ while $\varepsilon(X)$ refers to the inner porosity of the zeolite depending on the local water uptake $X$. The specific heat flux $\dot{q}$ denotes the heat transport by conduction and $h_{\mathrm{v}}$ refers to the specific enthalpy transported with the vapour.

In general, the specific internal energies are determined by

$$
e_{\mathrm{i}}=\int_{T_{\mathrm{ref}}}^{T} c_{\mathrm{i}}(\tilde{T}) \mathrm{d} \tilde{T}+e_{\mathrm{i}, \mathrm{ref}}
$$

where $c_{\mathrm{i}}$ denotes the specific heat capacity at constant volume of the substance and $e_{\mathrm{i} \text {,ref }}$ the specific internal energy of the substance at the reference temperature $T_{\text {ref }}$. The potential and kinetic energy are assumed to be negligible. While the specific heat capacity of the zeolite and vapour can be assumed constant over the integrated temperature range, the temperature dependency of the specific heat capacity of the adsorbate has been shown to be significant [24]. Hence, the approximation

$$
c_{\mathrm{a}}=c_{\mathrm{a}, \min }+\int_{T_{\min }}^{T} \alpha_{1} \exp \left[-\alpha_{2}\left(\tilde{T}-T_{\text {ref }}\right)^{2}\right] \mathrm{d} \tilde{T}
$$

from [24] is applied, where $c_{\mathrm{a} \text {,min }}$ refers to the minimum of the specific heat capacity at the temperature $T_{\min }$ while $\alpha_{1}$ and $\alpha_{2}$ are fitting parameters. At last, the Leibniz integral rule is used to evaluate the time derivative of the integral Eq. (12) in Eq. (11).

The variable porosity $\varepsilon(X)$ is given by

$$
\varepsilon(X)=\varepsilon_{\max }-\frac{\rho_{\mathrm{z}}}{\rho_{\mathrm{a}}} X
$$

where $\varepsilon_{\max }$ and $\rho_{\mathrm{a}}$ refer to the maximum porosity of the fully desorbed zeolite and to the density of the adsorbate respectively.

The specific heat flux is given by the Fourier law

$$
\dot{q}=-\lambda_{\mathrm{eff}} \frac{\partial T}{\partial z}
$$

where $\lambda_{\text {eff }}$ denotes the effective heat conductivity of the zeolite, adsorbate and the vapour. The effective heat conductivity is calculated according to

$$
\lambda_{\text {eff }}=\left(1-\varepsilon_{\max }\right) \lambda_{\mathrm{z}}+\frac{\rho_{\mathrm{z}}}{\rho_{\mathrm{a}}} X \lambda_{\mathrm{a}}+\left(\varepsilon(X)+\frac{A_{\mathrm{c}}}{A_{\mathrm{z}}}\right) \lambda_{\mathrm{v}}
$$


with $\lambda_{\mathrm{z}}, \lambda_{\mathrm{a}}$ and $\lambda_{\mathrm{v}}$ as heat conductivity of the pure zeolite, the adsorbate and the vapour.

Under the assumption of a constant specific heat capacity the spatial derivative of the specific enthalpy of the vapour can be calculated from

$$
\frac{\partial h_{\mathrm{v}}}{\partial z}=c_{p, \mathrm{v}} \frac{\partial T}{\partial t}
$$

where $c_{p, \mathrm{v}}$ denotes the specific heat capacity of the vapour at constant pressure.

The specific enthalpy of the vapour itself needs to be substituted by the thermodynamic potential with the ideal gas law (4)

$$
h_{\mathrm{v}}=e_{\mathrm{v}}+p v_{\mathrm{v}}=e_{\mathrm{v}}+R_{\mathrm{s}} T,
$$

where $v_{\mathrm{v}}$ denotes the specific volume of the vapour.

With the specific enthalpy of the adsorbate

$$
h_{\mathrm{a}}=e_{\mathrm{a}}+p v_{\mathrm{a}},
$$

where $v_{\mathrm{a}}$ denotes the specific volume of the adsorbate, and by taking the ideal gas law (4) and Eq. (18) into account the specific internal energy of the adsorbate can be substituted by

$$
\begin{aligned}
e_{\mathrm{a}}=e_{\mathrm{v}}+p \underbrace{\left(v_{\mathrm{v}}-v_{\mathrm{a}}\right)}_{v_{\mathrm{v}} \gg v_{\mathrm{a}}}- & \underbrace{\left(h_{\mathrm{v}}-h_{\mathrm{a}}\right)}_{=\Delta h_{\mathrm{a}}} \\
& \approx e_{\mathrm{v}}-\underbrace{\left(\Delta h_{\mathrm{a}}-R_{\mathrm{s}} T\right)}_{\Delta h_{\mathrm{a}} \gg R_{\mathrm{s}} T} \approx e_{\mathrm{v}}-\Delta h_{\mathrm{a}}
\end{aligned}
$$

to incorporate the heat of adsorption $\Delta h_{\mathrm{a}}$. The last approximation $\Delta h_{\mathrm{a}} \gg R_{\mathrm{s}} T$ is valid in the expected temperature range of $20 \ldots 200^{\circ} \mathrm{C}$ with an maximum error of $\approx 5 \%$.

At last, the continuity equation of the vapour in the channel and in the void space of the zeolite

$$
\frac{\partial}{\partial t}\left(\frac{A_{\mathrm{c}}}{A_{\mathrm{z}}} \rho_{\mathrm{v}}+\varepsilon(X) \bar{\rho}_{\mathrm{v}, \mathrm{z}}\right)+\frac{A_{\mathrm{c}}}{A_{\mathrm{z}}} \frac{\partial}{\partial z}\left(\rho_{\mathrm{v}} u\right)=-\frac{\mathrm{d} \dot{m}_{\mathrm{a}}}{\mathrm{d} V}
$$

has to be incorporated into the energy balance Eq. (11) to eliminate the specific internal energy of the vapour $e_{\mathrm{v}}$. The term $\mathrm{d} \dot{m}_{\mathrm{a}} / \mathrm{d} V$ denotes the volumetric mass flow rate in the zeolite due to the adsorption and is discussed in following section and given by Eq. (25).

\subsubsection{Adsorption}

The modelling of the adsorption comprises the mathematical description of the adsorption kinetics, adsorption equilibrium and the heat of adsorption.

Adsorption Kinetics. The adsorption kinetics implicitly describe the inter-particle mass transport of the vapour in the zeolite. As discussed in [17] the pressure profile can be assumed to be of parabolic shape over the radius while the local water uptake is at equilibrium. Further, radially isothermal condition in the adsorbent and a linear dependency of the adsorption equilibrium over the pressure have to be assumed. Under this assumptions the well-known linear-driving-force approximation

$$
\frac{\partial X}{\partial t}=k_{\mathrm{a}}\left(X_{\mathrm{eq}}-X\right)
$$

can be derived for various symmetrical adsorbents, where $k_{\mathrm{a}}$ denotes the adsorption kinetics parameter and $X_{\text {eq }}$ refers to the adsorption equilibrium corresponding to the pressure and temperature at the surface of the adsorbent.

For the adsorption kinetics parameter of a hollow cylindrical adsorbent the equation

$$
k_{\mathrm{a}}=4 D_{\mathrm{eff}}\left(\frac{\frac{5}{6} \gamma^{4}-2 \gamma^{3}+\gamma^{2}+\frac{2}{3} \gamma-\frac{1}{2}}{\gamma-1} \frac{d_{\mathrm{i}}^{2}}{4}\right)^{-1}
$$

is derived in [17], where $\gamma$ denotes the aspect ratio of the outer to inner diameter $d_{\mathrm{o}} / d_{\mathrm{i}}$ of the zeolite cut-out and $D_{\text {eff }}$ refers to the effective diffusivity off the water uptake in the zeolite. According to [25], the effective diffusivity can be determined from

$$
D_{\text {eff }}=\frac{D_{K n}}{\tau(1+\zeta)}=\frac{\frac{4}{3} d_{\mathrm{mp}} \sqrt{\frac{R_{\mathrm{s}} T}{2 \pi}}}{\tau\left(1+\frac{\rho_{\mathrm{z}}}{\varepsilon(X)} R_{\mathrm{s}} T \frac{\partial X_{\mathrm{eq}}}{\partial p}\right)}
$$

where $D_{K n}$ denotes the Knudsen diffusivity and $d_{\mathrm{mp}}$ refers to the mean macro pore diameter and $\tau$ to the mean tortuosity of the zeolite.

The volumetric mass flow rate of adsorption at a given position $z$ is simply calculated by

$$
\frac{\mathrm{d} \dot{m}_{\mathrm{a}}}{\mathrm{d} V}=\rho_{\mathrm{z}} \frac{\partial X}{\partial t} .
$$

Hence, the volumetric mass flow rate of the vapour from the channel into the void space of the zeolite can be derived from the continuity equation of the vapour in the zeolite

$$
\frac{\mathrm{d} \dot{m}_{\mathrm{c}, \mathrm{z}}}{\mathrm{d} t}=\rho_{\mathrm{z}} \frac{\partial X}{\partial t}+\frac{\partial}{\partial t}\left(\varepsilon(X) \bar{\rho}_{\mathrm{v}, \mathrm{z}}\right) .
$$

Under the assumption of local adsorption equilibrium inside the zeolite and by determination of the lower limits for the gradients of the isobars and isotherms of the water uptake in the expected range of pressure and temperature it can be shown that the vapour accumulation in the zeolite can be neglected

$$
\frac{\mathrm{d} \dot{m}_{\mathrm{c}, \mathrm{z}}}{\mathrm{d} t} \approx \rho_{\mathrm{z}} \frac{\partial X}{\partial t} .
$$

Adsorption Equilibrium. It has been shown in [6] that adsorption equilibrium for the adsorption of water on zeolite $13 \mathrm{X}$ can be described by the Dubinin-Astakhov equation

$$
X_{\mathrm{eq}}=\rho_{\mathrm{a}} v_{\mathrm{a}, \max } \exp \left[-\left(\frac{R_{\mathrm{s}} T \ln \left(\frac{p_{\mathrm{s}}}{p}\right)}{E}\right)^{n}\right]
$$

where $\rho_{\mathrm{a}} v_{\mathrm{a}, \max }$ corresponds to the maximum adsorption volume, $p_{\mathrm{s}}$ denotes the saturation pressure of the vapour, $E$ is the characteristic energy and $n$ the heterogeneity parameter. The density of the adsorbate is calculated from

$$
\rho_{\mathrm{a}}=\frac{\rho_{\mathrm{a}, 20^{\circ} \mathrm{C}}}{1+\beta(T-293.15 \mathrm{~K})}
$$

where $\beta$ denotes the coefficient of thermal expansion of the adsorbate. 
Heat of Adsorption. In contrast to many publications the dependency of the heat of adsorption on the uptake is taken into account in this study. The heat of adsorption can be determined by evaluation of the vant-Hoff equation [26] and leads to

$$
\Delta h_{\mathrm{a}}=\Delta h_{\mathrm{e}}+E \ln \left(\frac{\rho_{\mathrm{a}} v_{\mathrm{a}, \mathrm{max}}}{X_{\mathrm{eq}}}\right)^{\frac{1}{n}}
$$

where $\Delta h_{\mathrm{e}}$ denotes the heat of evaporation.

\subsection{System of Equations}

The modelling equations given in the Sect. 2.2 can be assembled to a system of coupled partial differential equations for the vapour pressure $p$, the temperature $T$ and the water uptake $X$. With $\partial_{t}:=\partial \cdot / \partial t$ and $\partial_{z}:=\partial \cdot / \partial z$ the system can be written as

$$
\begin{gathered}
\left(\begin{array}{ccc}
\frac{1}{R_{\mathrm{s}} T} & -\frac{p}{R_{\mathrm{s}} T^{2}} & \frac{A_{\mathrm{z}}}{A_{\mathrm{c}}} \rho_{\mathrm{z}} \\
0 & \left(\rho_{\mathrm{z}} c_{\mathrm{z}}+\rho_{\mathrm{z}} X c_{\mathrm{a}}\right) & -\rho_{\mathrm{z}} \Delta h_{\mathrm{a}} \\
0 & 0 & 1
\end{array}\right) \cdot\left(\begin{array}{l}
\partial_{t} p \\
\partial_{t} T \\
\partial_{t} X
\end{array}\right)= \\
\left(\begin{array}{c}
\partial_{z}\left(\rho_{\mathrm{v}} u\right) \\
\partial_{z}\left(\lambda_{\mathrm{eff}} \partial_{z} T\right)-\frac{A_{\mathrm{c}}}{A_{\mathrm{z}}} \rho_{\mathrm{v}} u c_{p, \mathrm{v}} \partial_{z} T-\frac{A_{\mathrm{c}}}{A_{\mathrm{z}}} R_{\mathrm{s}} T \partial_{z}\left(\rho_{\mathrm{v}} u\right) \\
k_{\mathrm{a}}\left(X_{\mathrm{eq}}-X\right)
\end{array}\right)
\end{gathered}
$$

Left of the equality sign, $c_{\mathrm{a}}$ is given by (13) and $\Delta h_{\mathrm{a}}$ by (30). Right of the equality sign, $\rho_{\mathrm{v}}$ is given by (4), $u$ either by (6) or by (8) with (10), $\lambda_{\text {eff }}$ by (16) and $k_{\mathrm{a}}$ by (23) with (24). All other parameters have constant values.

It should be emphasised that the last two terms in the heat transport equation (2nd row) are not included in most of the models found in literature. The first term of this two terms takes the convective energy transport by the vapour into account while the second term describes the cooling or heating effect due to expansion and compression of the vapour respectively.

\subsection{Model Verification}

As mentioned in the literature review in Sect. 1.2 no experimental study of closed low-pressure adsorption systems with zeolite honeycomb adsorbents is known to the authors. Hence, no validation of the full model is possible at this time. However, the model can be verified by separate validation of the main equations for mass transport, heat transport and adsorption. Since the novel aspect of our model in comparison to existing models for open adsorption systems is mainly given by the mass transport model, the focus is on the validation of the implemented equations for the mass transport.

\subsubsection{Mass Transport}

The implemented equations for the mass transport are formulated to describe precisely the mass flow rate $\dot{m}_{\mathrm{c}}$ over the full range of the Knudsen number. The mass flow rate over a broad range of the Knudsen number in a circular micro-tube is experimentally studied in [27]. There, the authors study the stationary flow of nitrogen through a micro-tube with a length of $L=5.3 \mathrm{~cm}$ and a diameter of $25.2 \mu \mathrm{m}$ at different in- and outlet pressures. Adjusting our numerical implementation to this

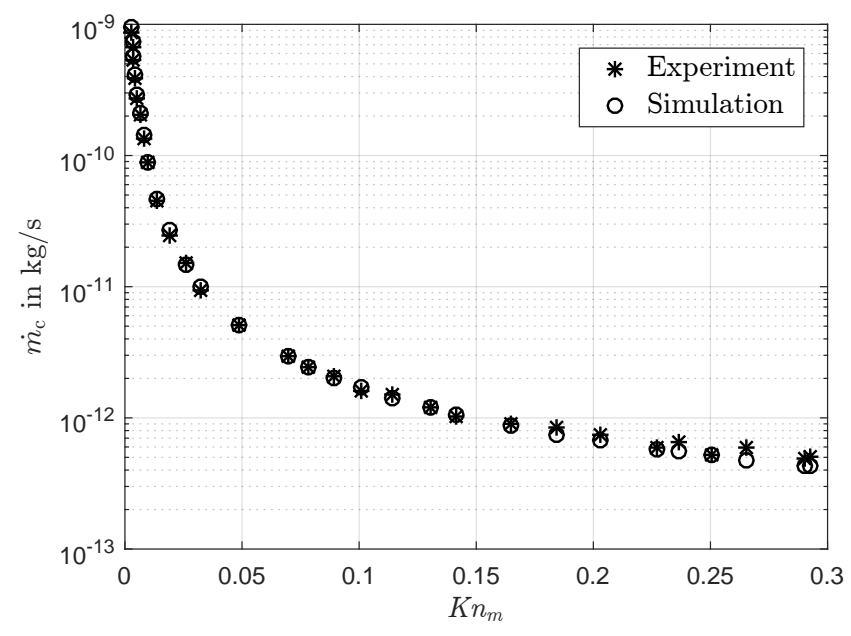

Figure 5: Comparison of simulation and experimental results for the stationary mass flow rate $\dot{m}_{\mathrm{c}}$ of nitrogen through a circular micro-tube at different mean Knudsen numbers. Experimental parameters and results are taken from [27].

case (nitrogen channel flow without adsorption) allows for direct comparison of our simulation results with the experiment. The results are depicted in Fig. 5 over the mean Knudsen number $K n_{m}$ calculated as in [27]. The simulation results show very good agreement with the experimental values. Thus, the implemented mass transport equations can be assumed valid.

\subsubsection{Heat Transport and Adsorption}

The implemented equations for the heat transport are very similar to most modelling approaches for adsorbers in literature, compare e. g. [9]. Only the last term in the heat transport equation (2nd row in Eq. (31)) which accounts for temperature change by expansion or compression respectively of the vapour is not considered. Evaluation of the magnitude of the single terms in the heat transport equation reveals that the last term is circumstantial for the studied cases.

The implemented equations for the adsorption are taken from [6]. Only the kinetics coefficient $k_{\mathrm{a}}$ of the linear driving force equation (22) is adjusted to the case of a hollow cylinder adsorbents according to [17].

Comparison of our model for the heat transport and adsorption with the model derived in [6] confirms the model similarity. The model is experimentally validated in [6] and good agreement between the simulation and experimental results is found. Hence, the implemented equations for the heat transport and adsorption is this study can be assumed valid.

\section{Numerical Implementation}

\subsection{Solving Method}

To numerically solve the system of equations (31), the righthand side is discretised by the finite-difference-method applying the central difference approximation [28]. Further, an adaptive mesh method is implemented to reduce the computational time. The criteria for the mesh adaption are the maximal allowed differences of pressure and temperature values between 
two neighbouring knots and are set to

$$
\Delta p \leq 50 \mathrm{~Pa}, \Delta T \leq 1 \mathrm{~K}
$$

Furthermore, the aspect ratio of the knot spacing $\Delta z$ of neighbouring knots is limited to 2 and the knot spacing at the boundaries is fixed to the initial and minimum knot spacing $\Delta z_{\min }$. Comparative simulations with no mesh adaption prove, that the mesh adaption leads to no significant deviations. The reduction of the computational time by the mesh adaption depends on the applied initial and minimal knot spacing. For $\Delta z_{\min }=L / 500$ the mesh adaption leads to a reduction of the computational time by a factor of 2.2 and 3.8 respectively for the two cases of the mesh study given in Tab. A.2. For $\Delta z_{\min }=L / 1000$ the computational time of the second case is even reduced by a factor of 10 .

To prove mesh independence of the results, a mesh study is conducted for two representative cases of low and high dynamic behaviour, see Tab. A.2. The mesh study yields that an initial and minimal knot spacing of $\Delta z_{\min }=L / 500$ is sufficient.

Regarding the time integration, the evaluation of the matrix on the left-hand side of the system of equations (31) for the possible pressure and temperature values yields a wide range of the order of magnitude of the matrix elements

$$
\left\{\frac{p}{R_{\mathrm{s}} T^{2}}\right\} \approx 10^{-9} \ldots\left\{\rho_{\mathrm{z}} \Delta h_{\mathrm{a}}\right\} \approx 10^{9} .
$$

Hence, the system can be expected to be stiff [29]. For the time integration the ode-solver for stiff systems ode15s of Matlab (see [30] for solver description) is successfully applied. At last, the matrix is an upper triangular matrix which allows for a sequential evaluation of the single equations in each time step.

\subsection{Simulation Case Setup}

As motivated in Sect. 1.3 simulations are carried out for a broad range of parameters. The varied parameters, according to Fig. 4, are given in Tab. 1. With the geometry transformation relations given in [17] the examined axially symmetric channel corresponds to a channel width of a square channel of $a=(0.4 ; 0.8 ; 1.6) \mathrm{mm}$ and a width of the square zeolite cutout of $(1.6 ; 2.2 ; 3.3) \cdot a$. This covers a typical range of feasible channel diameters and web thickness of zeolite honeycombs, see Sect. 1.2. As initial conditions (IC) states of equilibrium are defined, as they would appear in a closed zeolite adsorber after extraction of the sensible heat with a closed inlet after desorption, see Sect. 2.1. The boundary conditions (BC) are chosen in accordance with typical operating conditions for seasonal storage of solar energy for domestic heating. The material parameters are mostly taken from [6] and [31] and are summarised in the appendix.

\section{Results and Discussion}

In accordance with the model description in Sect. 2, the results are discussed separately for the mass transport, heat transport and adsorption to answer the questions specified in
Table 1: Varied geometry and process parameters of the studied simulation

\begin{tabular}{|c|c|c|c|}
\hline & Parameter & Value & Unit \\
\hline \multirow{3}{*}{ 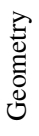 } & $d_{\mathrm{i}}$ & $0.5 ; 1.0 ; 2.0$ & $\mathrm{~mm}$ \\
\hline & $d_{\mathrm{o}}$ & $(1.5 ; 2.0 ; 3.0) \cdot d_{\mathrm{i}}$ & $\mathrm{mm}$ \\
\hline & $L$ & $0.01 ; 0.1 ; 1.0$ & $\mathrm{~m}$ \\
\hline \multirow{3}{*}{$\varrho$} & $p_{0}$ & $0.001 ; 0.1$ & mbar \\
\hline & $T_{0}$ & $20 ; 50$ & ${ }^{\circ} \mathrm{C}$ \\
\hline & $X_{0}=X_{\mathrm{eq}}$ & $0.055 ; 0.10 ; 0.15 ; 0.21$ & $\mathrm{~kg} / \mathrm{kg}$ \\
\hline \multirow{3}{*}{ U } & $p_{\text {in }}$ & $10 ; 20$ & mbar \\
\hline & $T_{\text {in }}=T_{\mathrm{s}}$ & $7 ; 17.5$ & ${ }^{\circ} \mathrm{C}$ \\
\hline & $T_{\mathrm{htx}}$ & 20 & ${ }^{\circ} \mathrm{C}$ \\
\hline
\end{tabular}
cases. ( $\mathrm{IC}=$ initial conditions; $\mathrm{BC}=$ boundary conditions $)$

Sect. 1.3. The answers apply to the studied adsorber system described in Sect. 2.1. For a better comparability of the results, the non-dimensional time

$$
\tilde{t}:=\frac{t}{t_{\mathrm{tot}}}
$$

is defined, where $t_{\text {tot }}$ denotes the total process duration. The process is defined to be completed when the temperature at the inlet has decreased to a temperature of less than $1 \mathrm{~K}$ above the temperature of the heat exchanger $T_{\mathrm{htx}}$. Regarding the graphical evaluation of the results, all specified parameters are given in the figures while the plotted curves or ranges correspond to all simulation cases of the non-specified parameters. Furthermore, most of the graphical results correspond to a inlet pressure of $p_{\text {in }}=10 \mathrm{mbar}$. The influence of the inlet pressure is only discussed if relevant.

\subsection{Mass Transport}

One specific aspect of our model regarding the mass transport of the vapour in the channel is, that it takes specific effects of rarefied gas flow, such as slip, into account. To evaluate whether such effects need to be considered in the examined cases, the occurring values of the Knudsen number are analysed. In general, higher Knudsen numbers can be expected for lower inlet pressures. Hence, the range of the Knudsen number $K n$ in the vapour channel as a function of the non-dimensional time $\tilde{t}$ for different channel diameters $d_{\mathrm{i}}$ is given for the lower inlet pressure of $p_{\text {in }}=10$ mbar in Fig. 6. Initially, the Knudsen number even exceeds the slip regime before rapidly decreasing to the slip / no-slip limit. For a channel diameter of $d_{\mathrm{i}}=0.5 \mathrm{~mm}$ the Knudsen number remains in the slip regime over the whole process duration. This indicates, that the slip effect might be relevant for this minimal channel diameter and inlet pressure.

The evolution of the pressure $p(z, \tilde{t})$ in the vapour channel for a specific example is shown in Fig. 7.The concave shape of the advancing pressure is similar to the concave shape of compressible channel flow described in the literature, e.g. [32]. Further, it is clear, that the vapour reaches the end of the channel in a relatively short time with respect to the total process duration (here $\tilde{t}<1 \%$ ). This raises the question whether the assumption 


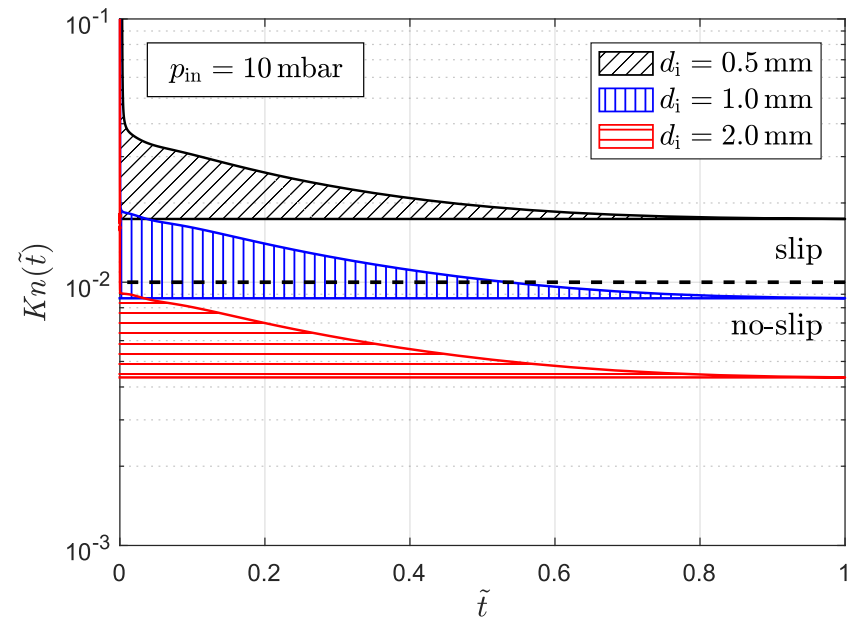

Figure 6: Range of the Knudsen number $K n$ in the vapour channel versus the non-dimensional time $\tilde{t}$ at different channel diameters $d_{\mathrm{i}}$ for the lower inlet pressure of $p_{\text {in }}=10 \mathrm{mbar}$.

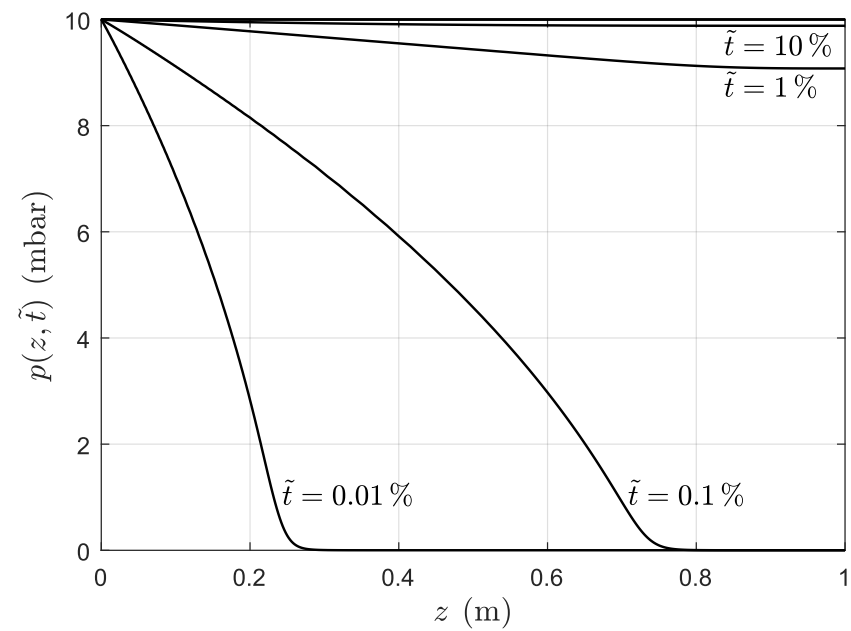

Figure 7: Evolution of the pressure $p(z, \tilde{t})$ in the vapour channel for the specific example $p_{\text {in }}=10 \mathrm{mbar}, p_{0}=0.001 \mathrm{mbar}, T_{0}=20^{\circ} \mathrm{C}, X_{0}=0.055 \mathrm{~kg} / \mathrm{kg}$, $d_{\mathrm{i}}=0.5 \mathrm{~mm}, d_{\mathrm{o}}=3 d_{\mathrm{i}}\left(\varepsilon_{\mathrm{c}}=0.11\right), L=1 \mathrm{~m}$.

of creeping flow $(R e \ll 1)$ is valid. Analysis of all simulated cases yield, that in fact the Reynolds number initially reaches very high values $\left(R e \approx 10^{4}\right)$, but drops significantly below 1 for $\tilde{t} \geq 0.001 \%$. Hence, the assumption of creeping flow is valid after a very short relative time.

The evolution of the Knudsen number $K n(z, \tilde{t})$ in the vapour channel for the same specific example is shown in Fig. 8. For a short relative time $\tilde{t}<1 \%$ the Knudsen number ranges from the slip region over the transition region far into the free molecular region. Comparison with the evolution of the water uptake in Fig. 15 reveals, that the advancing adsorption front lies in the range of the transition regime. It is not clear whether or how this might affect the adsorption process. At last, as the pressure in the vapour channel increases fast, the Knudsen number also decreases fast into the slip region over the whole channel length. For $\tilde{t} \geq 1 \%$ the Knudsen number is mainly determined by the temperature, thus yielding similar profiles (compare Fig. 12).

To discuss whether isobaric conditions can be assumed

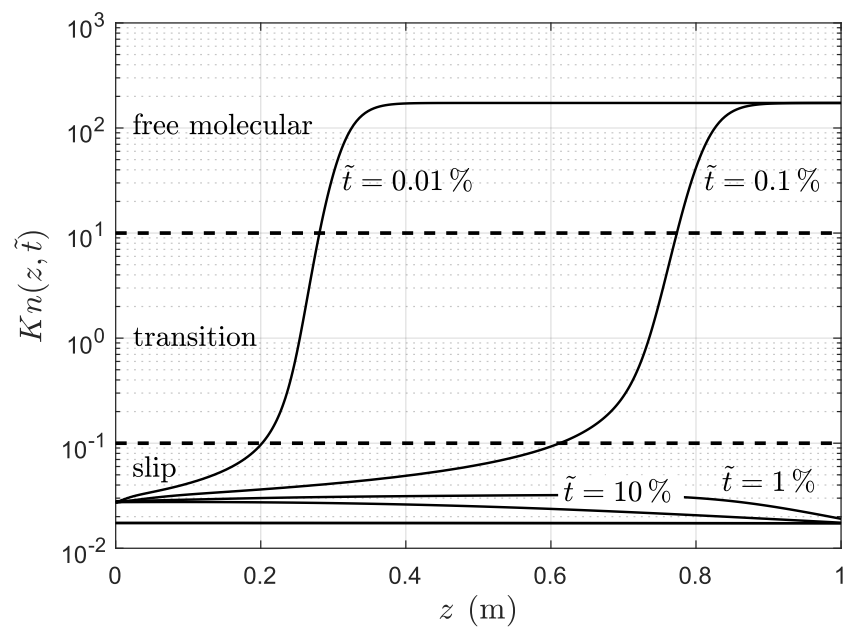

Figure 8: Evolution of the Knudsen number $K n(z, \tilde{t})$ in the vapour channel for the specific example $p_{\text {in }}=10 \mathrm{mbar}, p_{0}=0.001 \mathrm{mbar}, T_{0}=20^{\circ} \mathrm{C}, X_{0}=$ $0.055 \mathrm{~kg} / \mathrm{kg}, d_{\mathrm{i}}=0.5 \mathrm{~mm}, d_{\mathrm{o}}=3 d_{\mathrm{i}}\left(\varepsilon_{\mathrm{c}}=0.11\right), L=1 \mathrm{~m}$.

throughout the whole process or whether the mass transport of the vapour in the channel has to be taken into account, the variation of the pressure at the end of the channel can be analysed. In Fig. 9 the variation of the pressure at the end of the channel $p(L, \tilde{t})$ as a function of the non-dimensional time $\tilde{t}$ at different channel diameters $d_{\mathrm{i}}$ is given for the lower inlet pressure of $p_{\text {in }}=10 \mathrm{mbar}$. While the condition for creeping flow $(R e \ll 1)$ is met for $\tilde{t} \geq 10^{-6}$ in the case of a channel diameter of $d_{\mathrm{i}}=0.5 \mathrm{~mm}$ and $d_{\mathrm{i}}=1 \mathrm{~mm}$, it is met strictly only for $\tilde{t} \geq 10^{-5}$ in the case of a channel diameter of $d_{\mathrm{i}}=2 \mathrm{~mm}$. Besides the solution range for every channel diameter, one specific example is depicted with a solid line each. It is observed, that for a short period of relative time the pressure at the end of the channel does not increase (pressure plateau). This effect results from a temporary equilibrium of vapour flow into the channel and adsorption by the zeolite. Similar characteristics is observed for the higher inlet pressure $p_{\text {in }}=20 \mathrm{mbar}$. As to the authors knowledge, this effect has not been reported in literature. Variation of the parameters show that the height of the pressure plateau depends on the zeolite properties. Hence, this phenomena might offer a novel experimental method to determine microscopic material properties such as porosity, tortuosity, and mean macro-pore diameter.

All simulated cases show, that the pressure at the end of the channel increases to $99 \%$ of the inlet pressure in less than $20 \%$ of the total process time. The required relative time is defined as $\tilde{t}_{p, 99}:=t_{p, 99} / t_{\text {tot }}$. The range of $\tilde{t}_{p, 99}$ as a function of the channel diameter $d_{\mathrm{i}}$ at different aspect ratios of outer to inner diameter $\gamma$ (corresponding to a channel porosity $\varepsilon_{\mathrm{c}}$ of the honeycomb structure) is given for the lower inlet pressure of $p_{\text {in }}=10 \mathrm{mbar}$ in Fig. 10. For channel diameters $d_{\mathrm{i}} \geq 1 \mathrm{~mm}$ and aspect ratios of $\gamma \leq 2\left(\varepsilon_{\mathrm{c}} \geq 0.25\right)$ the assumption of isobaric conditions throughout the whole process is fairly met since $\tilde{t}_{p, 99} \leq 2 \%$. For a channel diameter of $d_{\mathrm{i}}=0.5 \mathrm{~mm}$ the relative time $\tilde{t}_{p, 99}$ increases significantly, with $\tilde{t}_{p, 99}$ lying in the range of $\approx 5 \ldots 16 \%$ for an aspect ratio of $\gamma=3\left(\varepsilon_{\mathrm{c}}=0.11\right)$. Hence, the assumption of isobaric conditions throughout the whole process is arguable 


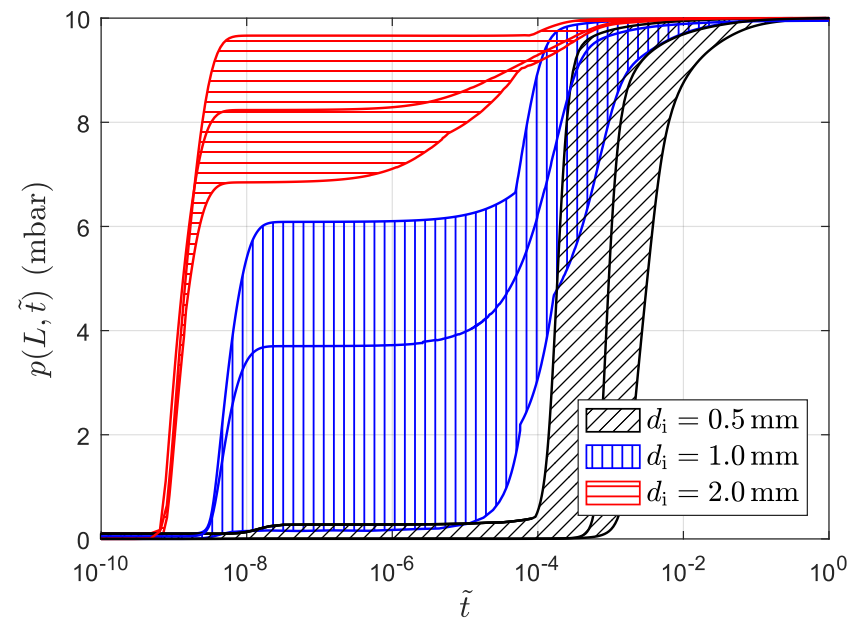

Figure 9: Variation of the pressure at the end of the channel $p(L, \tilde{t})$ versus the non-dimensional time $\tilde{t}$ at different channel diameters $d_{\text {i }}$ for the lower inlet pressure of $p_{\text {in }}=10 \mathrm{mbar}$. The three shaded areas mark the solution range for the different initial conditions, channel lengths $L$ and outer diameters $d_{\mathrm{o}}$. The solid lines in each shaded area show one example of the pressure variation at the end of the channel.

for this limit cases. Regarding the case of higher inlet pressure $p_{\text {in }}=20$ mbar, the relative time $\tilde{t}_{p, 99}$ reduces approximately by the factor of 3. Furthermore, the variation of the relative time $\tilde{t}_{p, 99}$ for a defined channel diameter and aspect ratio of the outer to inner diameter results from the variation of the initial conditions. It is found, that the relative time $\tilde{t}_{p, 99}$ linearly decreases with increasing initial water uptake $X_{0}=X_{\text {eq }}\left(p_{0}, T_{0}\right)$. This follows from the variation of the adsorption capacity which decreases with an increasing initial water uptake.

To conclude the mass transport analysis, the total process duration is analysed. The range of the total process duration $t_{\text {tot }}$ as a function of the channel diameter $d_{\mathrm{i}}$ at different channel length $L$ is given for both, no-slip and slip approach (see Sect. 2.2.1), and for the lower inlet pressure of $p_{\text {in }}=10 \mathrm{mbar}$ in Fig. 11. It is clear, that even for the minimal channel diameter $d_{\mathrm{i}}=0.5 \mathrm{~mm}$ no significant difference is found between the solutions of the no-slip and slip approach. In addition, the total process duration is found not to depend on the channel diameter nor on the aspect ratio of the outer to inner diameter for channel lengths of $L \geq 0.1 \mathrm{~m}$. This indicates, that the total process duration is solely determined by the heat transport and is not limited either by the mass transport or the adsorption. Only for the minimal channel length $L=0.01 \mathrm{~m}$ the maximum process duration linearly increases with the channel diameter. Since the process duration would be expected to decrease with increasing channel diameter, the dependency of the total process duration cannot be a result of mass transport limitations. Consequently, the increase of the total process duration with the channel diameter results from the increased web thickness of the zeolite. Hence, the observed increase of the total process duration as a function of the channel diameter for a minimum channel length of $L=0.01 \mathrm{~m}$ is a result of limitation by the adsorption process.

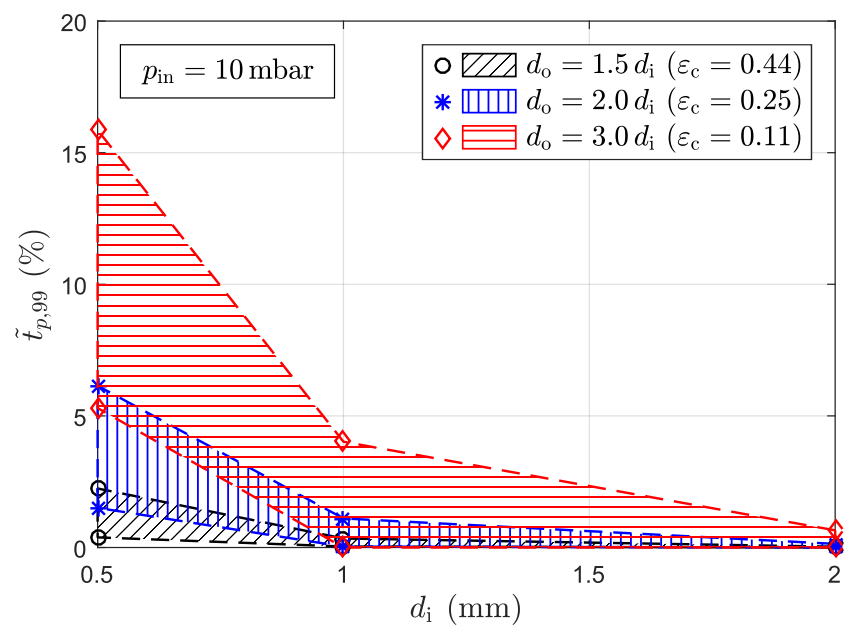

Figure 10: Range of $\tilde{t}_{p, 99}$ versus the channel diameter $d_{\mathrm{i}}$ at different aspect ratios of outer to inner diameter $\gamma$ (corresponding to channel porosity $\varepsilon_{\mathrm{c}}$ ) for the lower inlet pressure of $p_{\text {in }}=10 \mathrm{mbar}$.

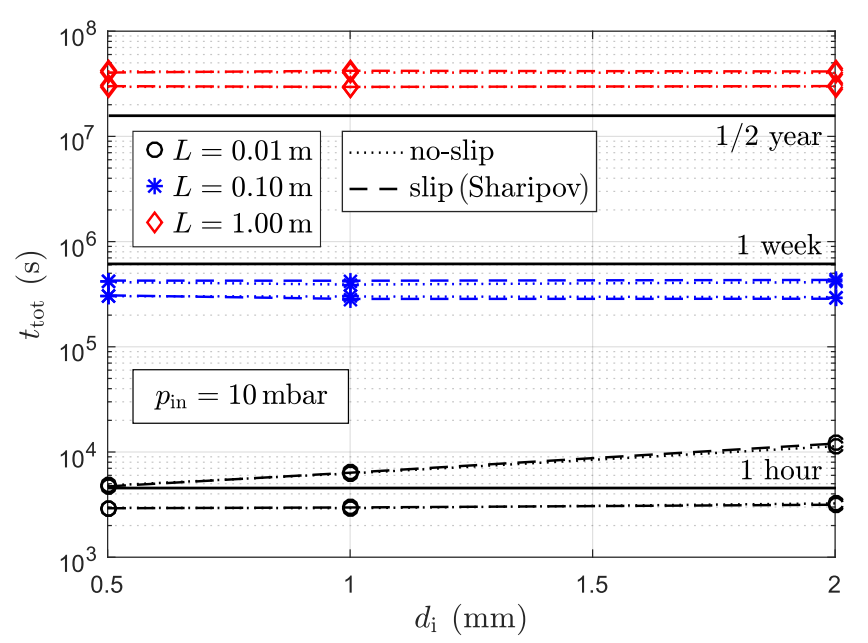

Figure 11: Range of total process duration $t_{\text {tot }}$ versus the channel diameter $d_{\mathrm{i}}$ at different channel length $L$ for no-slip and slip approach (see Sect. 2.2.1) and for the lower inlet pressure of $p_{\text {in }}=10 \mathrm{mbar}$.

\subsection{Heat Transport}

The evolution of the temperature $T(z, \tilde{t})$ for the specific example as before for the mass transport analysis is shown in Fig. 12. In accordance with the evolution of the pressure in the vapour channel (see Fig. 7) the temperature increases due to the adsorption process, yielding a relatively steep advancing temperature front. Again, the relative time required for the temperature front to reach the end of the channel is low with $\tilde{t}<1 \%$. The rest of the process is characterized by a temperature decrease due to the heat extraction at the end of the channel. While the temperature decreases throughout the adsorber the adsorption continues. Furthermore, a significant convective cooling by the inflowing cold vapour is observed for $\tilde{t} \leq 1 \%$ leading to a temperature difference $\Delta T$ between the maximum temperature in the adsorber and the temperature at the inlet. For $\tilde{t}>1 \%$ the mass flow rate of the inflowing vapour drops significantly, thus the convective cooling by the inflowing vapour becomes negligible for the specific example. 


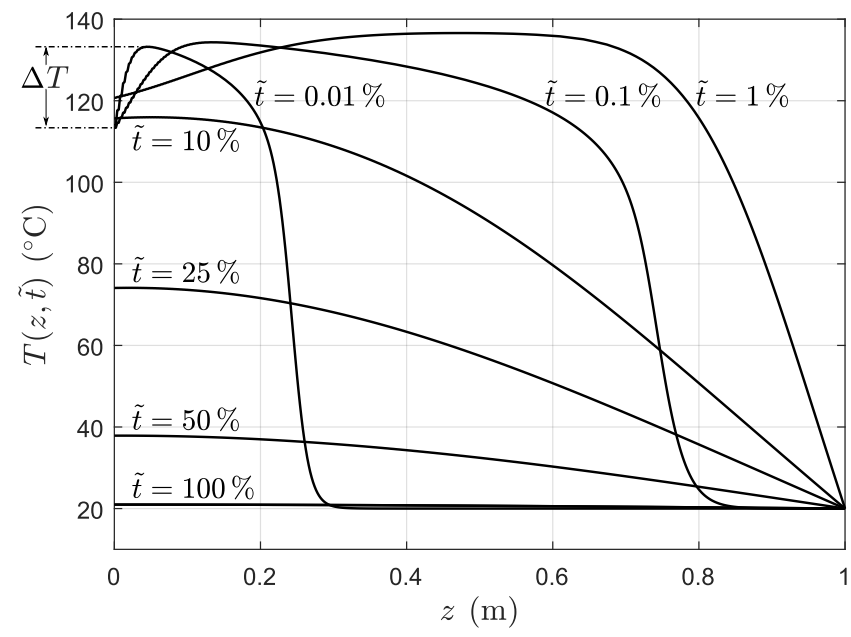

Figure 12: Evolution of the temperature $T(z, \tilde{t})$ for the specific example $p_{\text {in }}=$ $10 \mathrm{mbar}, p_{0}=0.001 \mathrm{mbar}, T_{0}=20^{\circ} \mathrm{C}, X_{0}=0.055 \mathrm{~kg} / \mathrm{kg}, d_{\mathrm{i}}=0.5 \mathrm{~mm}, d_{\mathrm{o}}=$ $3 d_{\mathrm{i}}\left(\varepsilon_{\mathrm{c}}=0.11\right), L=1 \mathrm{~m}$.

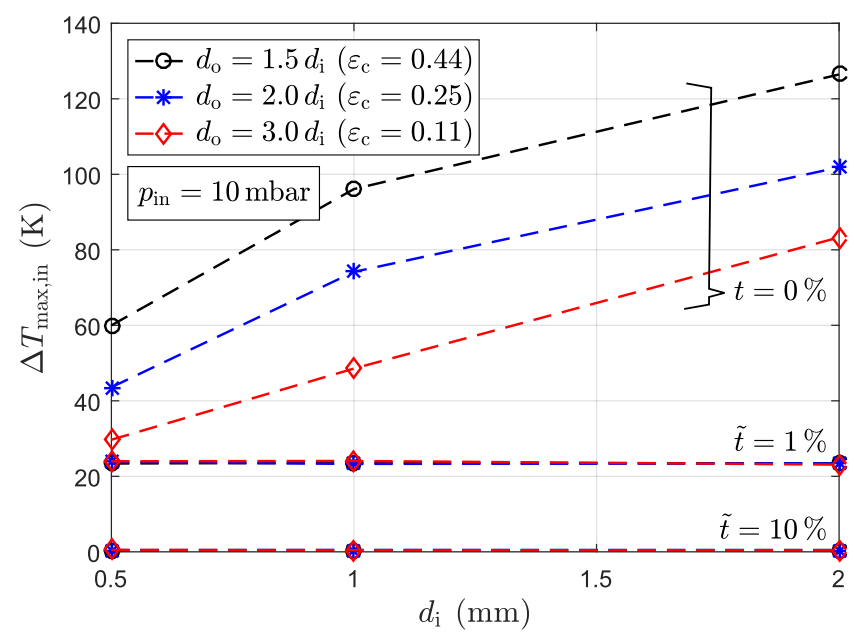

Figure 13: Maximum temperature difference between the maximum temperature in the adsorber and the temperature at the inlet $\Delta T_{\max , \text { in }}$ versus the channel diameter $d_{\mathrm{i}}$ at different aspect ratios of outer to inner diameter $\gamma$ (corresponding to channel porosity $\varepsilon_{\mathrm{c}}$ ) for different relative times $\tilde{t}$ for the lower inlet pressure of $p_{\text {in }}=10 \mathrm{mbar}$.

To discuss whether the convective cooling by the inflowing cold vapour is generally relevant, the maximum temperature difference between the maximum temperature in the adsorber and the temperature at the inlet $\Delta T_{\max \text {,in }}$ as a function of the channel diameter $d_{\mathrm{i}}$ at different aspect ratios of outer to inner diameter $\gamma$ (corresponding to a channel porosity $\varepsilon_{\mathrm{c}}$ of the honeycomb structure) is given for different relative times $\tilde{t}$ for the lower inlet pressure of $p_{\text {in }}=10 \mathrm{mbar}$ in Fig. 13. While initially the temperature difference is significant and reaches up to $\Delta T_{\max , \text { in }}>120 \mathrm{~K}$, the temperature difference decreases very fast to $\Delta T_{\max \text {,in }}<1 \mathrm{~K}$ after a relative time of $\tilde{t} \geq 10 \%$. Thus, the convective cooling is significant for the initial inflow process when the exact temperature distribution is of interest, but may be neglected with respect to the energy balance over the whole process duration.

The maximum temperature reached during the adsorption is

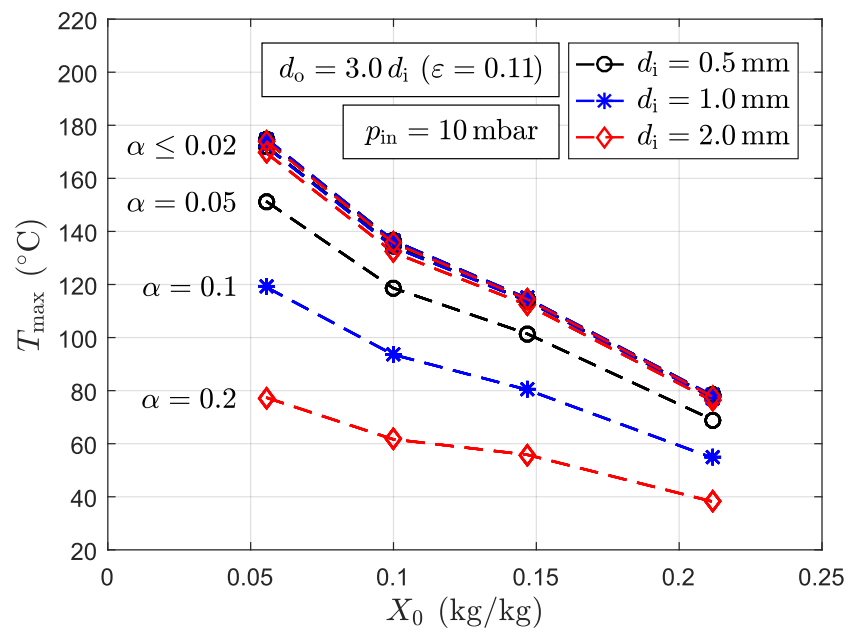

Figure 14: Variation of the maximum temperature $T_{\max }$ reached in the adsorber versus the initial water uptake $X_{0}$ at different channel diameters $d_{\mathrm{i}}$ for an aspect ratio of inner to outer channel diameter $\gamma=3$ (corresponding to channel porosity $\left.\varepsilon_{\mathrm{c}}=0.11\right)$ and for the lower inlet pressure of $p_{\text {in }}=10 \mathrm{mbar}$, with aspect ratio $\alpha:=d_{\mathrm{i}} / L$.

found to depend mainly on the initial water uptake. The variation of the maximum temperature $T_{\max }$ reached in the adsorber as a function of the initial water uptake $X_{0}$ at different channel diameters $d_{\mathrm{i}}$ is given for an aspect ratio of inner to outer channel diameter $\gamma=3$ (corresponding to a channel porosity $\varepsilon_{\mathrm{c}}=0.11$ of the honeycomb structure) and for the lower inlet pressure of $p_{\text {in }}=10 \mathrm{mbar}$ in Fig. 14. It is found, that for an aspect ratio $\alpha:=d_{\mathrm{i}} / L \leq 0.02$ the maximum temperature becomes independent of the aspect ratio $\alpha$ and of the channel diameter respectively. For increasing values of the aspect ratio $\alpha \geq 0.05$ the maximum temperature is found to reduce significantly. As observed before for the total process duration (see Fig. 11), the reduction of the maximum temperature indicates, that for this cases of $L=0.01 \mathrm{~m}$ the adsorption becomes the limiting factor for the maximum temperature reached in the adsorber. The limitation by adsorption results from the limitation of the microscopic mass transport (Knudsen diffusion) in the mciro-porous zeolite.

At last, the thermal power output is found to behave as expected. Initially, depending on the channel length, high peak values occur when the temperature front reaches the end of the channel $\dot{q}_{\text {out }} \approx 4 \cdot\left(10^{3} ; 10^{4} ; 10^{5}\right) \mathrm{W} / \mathrm{m}^{2}$, where the minimum power output corresponds to the maximum channel length and vice versa. After the peak of the power output, the power output decreases to $\dot{q}_{\text {out }} \approx 4 \cdot\left(10^{-1} ; 10^{0} ; 10^{1}\right) \mathrm{W} / \mathrm{m}^{2}$. The variation of the power output over a range of 4 orders of magnitude, indicates, that the examined adsorber set-up might not be of practical relevance in the framework of a single adsorber concept.

\subsection{Adsorption}

The evolution of the water uptake $X(z, \tilde{t})$ for the specific example as before for the mass and heat transport analysis is shown in Fig. 15. In accordance with the evolution of the pressure in the vapour channel (see Fig. 7) the water uptake increases due to the adsorption process, yielding an advancing 


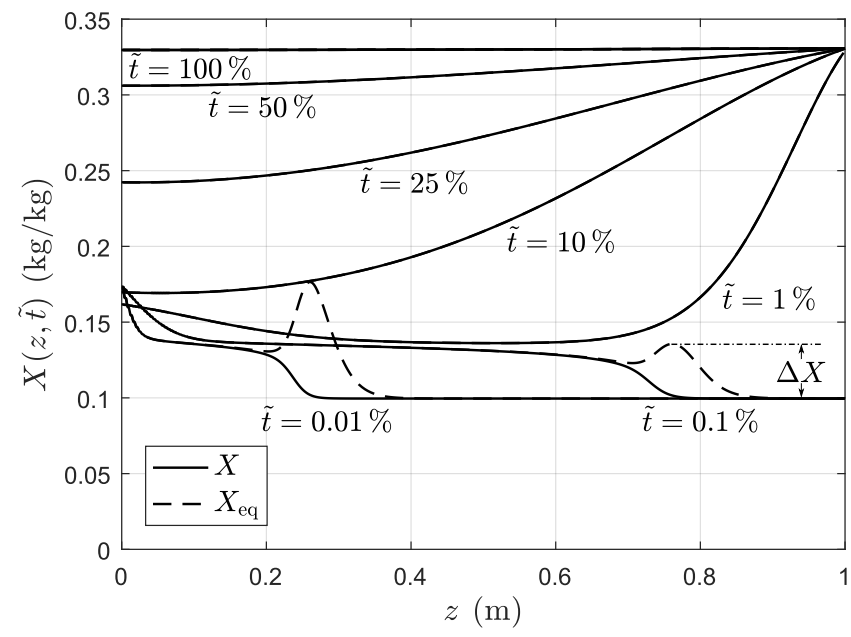

Figure 15: Evolution of the water uptake $X(z, \tilde{t})$ for the specific example $p_{\text {in }}=$ $10 \mathrm{mbar}, p_{0}=0.001 \mathrm{mbar}, T_{0}=20^{\circ} \mathrm{C}, X_{0}=0.055 \mathrm{~kg} / \mathrm{kg}, d_{\mathrm{i}}=0.5 \mathrm{~mm}, d_{\mathrm{o}}=$ $3 d_{\mathrm{i}}\left(\varepsilon_{\mathrm{c}}=0.11\right), L=1 \mathrm{~m}$.

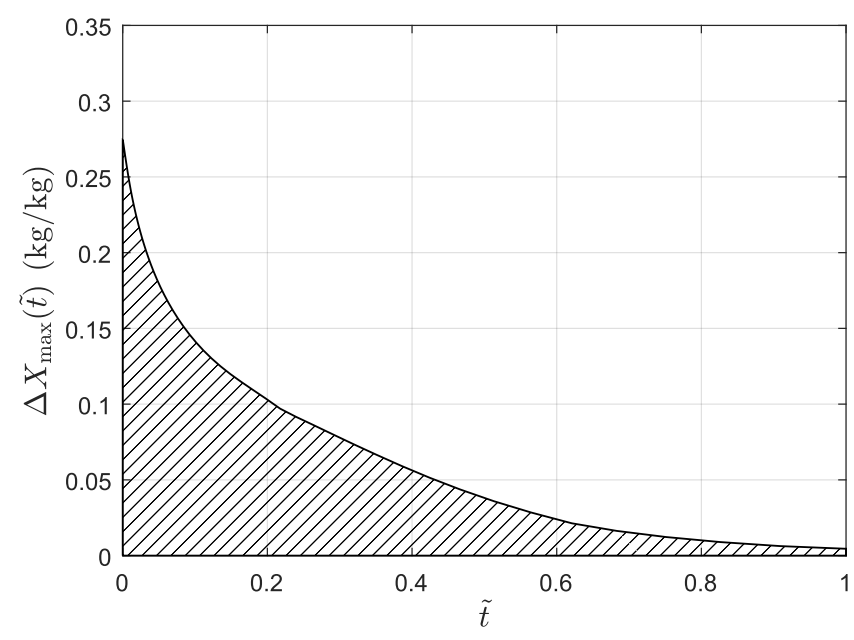

Figure 16: Range of the maximal difference between the actual water uptake and the water uptake equilibrium $\Delta X_{\max }$ versus time for all simulated cases.

uptake or adsorption front respectively. Again, the relative time required for the adsorption front to reach the end of the channel is low $\tilde{t}<1 \%$. The rest of the process is characterized by an increase of water uptake in accordance with the temperature decrease in the adsorber (see Fig. 12). Furthermore, the convective cooling by the inflowing cold vapour leads to an initially increased water uptake at the inlet. At last, the specific example shows that a significant difference between the actual water uptake and the adsorption equilibrium $\Delta X=X_{\text {eq }}-X$ exists locally in the area of the adsorption front, but vanishes after a short relative time of $\tilde{t} \leq 1 \%$. To discuss whether the assumption of local adsorption equilibrium is valid or whether the limitations by the adsorption kinetics are relevant, the range of the maximal difference between the actual water uptake and the adsorption equilibrium $\Delta X_{\max }$ as a function of time is given for all simulated cases in Fig. 16. Initially, the deviation from adsorption equilibrium can reach up to $\Delta X \approx 0.275$. During the process the maximal deviation from equilibrium decreases continuously. More detailed analysis yield, that for a channel length of $L \geq 0.1 \mathrm{~m}$ or an aspect ratio of channel diameter to channel length of $\alpha \leq 0.02$ respectively, the maximal deviation from equilibrium has decreased to less than $5 \%$ of the maximal possible deviation $(\Delta X \leq 0.017)$ after a relative time of $\tilde{t}=10 \%$. The maximal possible deviation is determined by the maximal possible water uptake which is $X_{\max }=0.34$ for the studied zeolite $13 X$. Hence, the assumption of local adsorption equilibrium can be justified for this cases. In case of a channel length of $L=0.01 \mathrm{~m}$ and especially for the maximum channel diameter of $d_{\mathrm{i}}=2 \mathrm{~mm}$ the assumption does not hold up. In this case, as discussed before (see Fig. 11 and Fig. 14), the process is limited by the adsorption and thus, the deviation from equilibrium must be considered.

\section{Conclusion and Outlook}

A closed low-pressure adsorber with zeolite $13 \mathrm{X}$ honeycomb adsorbent for thermal energy storage is studied numerically. The study is limited to the adsorption process with heat extraction at the end of the zeolite honeycomb arrangement (see Fig. 3). A detailed model which takes effects of rarefied gas flow (e.g. slip) as well as cooling effects by the inflowing vapour into account is derived. With respect to the specific questions formulated in Sect. 1.3 following results can be summarized:

Mass Transport:

- For all simulated cases (see Tab. 1) isobaric conditions are reached in less than $20 \%$ of the total process duration. Only for the cases with channel diameter of $d_{\mathrm{i}}=0.5 \mathrm{~mm}$ and a aspect ratio of outer to inner diameter of the zeolite channel of $\gamma=3\left(\varepsilon_{\mathrm{c}}=0.11\right)$ the duration of non-isobaric conditions can be considered significant with $\approx 5 \ldots 16 \%$ of the total process duration.

- With respect to the total process duration, effects of rarefied gas flow (e.g. slip) are found to be negligible in all studied cases due to the relatively wide channel diameters. Thus, the Darcy's law (no-slip) can be applied.

\section{Heat Transport:}

- For the duration of the advancing temperature front to reach the end of the channel, the convective cooling by the inflowing vapour significantly reduces the temperature at the inlet $\left(\Delta T_{\max , 0} \leq 140 \mathrm{~K}\right)$. But since this process requires less than $1 \%$ of the total process duration, the effect might be neglected with respect to the energy balance of the total process.

- The maximum temperature reached in the adsorber is primary determined by the initial water uptake and limited to the equilibrium temperature of adiabatic adsorption. Only for an aspect ratio of channel diameter to channel length $\alpha \geq 0.05$ or a channel length of $L=0.01 \mathrm{~m}$ respectively and an aspect ratio of outer to inner diameter $\gamma \geq 0.3\left(\varepsilon_{\mathrm{c}} \leq 0.11\right)$ the maximum temperature is found to 
decrease with an increasing aspect ratio $\alpha$. For this cases, the limitation by the adsorption exceeds the limitation by the heat transport.

\section{Adsorption:}

- In accordance with the limitation of the maximum temperature by the adsorption, the deviation from adsorption equilibrium is found to be significant for an aspect ratio of channel diameter to channel length of $\alpha \geq 0.05$ or a channel length of $L=0.01 \mathrm{~m}$ respectively.

Regarding further studies, the presented model should be extended to a two-dimensional model to study the more practical case of heat extraction orthogonal to the channels of the zeolite honeycomb arrangement. Further, the model could be applied to packed-bed adsorbers with small zeolite particle size (e.g. powders) to examine whether effects of rarefied gas flow become relevant in this cases. At last, the simulations yield the interesting effect of a temporary equilibrium of inflowing vapour and adsorption (pressure plateau). Since this effect might offer a novel option to determine material parameters of zeolite or other adsorbents, the phenomena should be experimentally validated.

\section{Acknowledgment}

The authors are grateful to the DLR colleagues M. Dieterich, N. Neumann, J. Stengler, M. Schmidt, C. Weckerle, I. Bürger and M. Linder for fruitful discussions and to M. Farahani for help with numerical issues.

\section{References}

[1] M. Linder, 14 - Using thermochemical reactions in thermal energy storage systems, in: L. F. Cabeza (Ed.), Advances in Thermal Energy Storage Systems : Woodhead Publishing Series in Energy, Woodhead Publishing, 2015, pp. 357-374. doi:10.1533/9781782420965.3.357.

URL http://www.sciencedirect.com/science/article/pii/ B9781782420880500146

[2] K. E. N'Tsoukpoe, G. Restuccia, T. Schmidt, X. Py, The size of sorbents in low pressure sorption or thermochemical energy storage processes, Energy 77 (2014) 983-998. doi : 10.1016/j . energy . 2014.10.013.

[3] K. E. N'Tsoukpoe, H. Liu, N. Le Pierres, L. Luo, A review on long-term sorption solar energy storage, Renewable \& Sustainable Energy Reviews 13 (9) (2009) 2385-2396. doi:10.1016/j.rser.2009.05.008.

[4] A. Pesaran, H. Lee, Y. Hwang, R. Radermacher, H.-H. Chun, Review article: Numerical simulation of adsorption heat pumps, Energy 100 (2016) 310-320. doi:10.1016/j.energy.2016.01.103.

[5] H. Schreiber, S. Graf, F. Lanzerath, A. Bardow, Adsorption thermal energy storage for cogeneration in industrial batch processes: Experiment, dynamic modeling and system analysis, Applied Thermal Engineering 89 (2015) 485-493. doi :10.1016/j.applthermaleng. 2015.06.016. URL http://www.sciencedirect.com/science/article/pii/ S1359431115005694

[6] B. Mette, H. Kerskes, H. Drück, H. Müller-Steinhagen, Experimental and numerical investigations on the water vapor adsorption isotherms and kinetics of binderless zeolite 13X, International Journal of Heat and Mass Transfer 71 (2014) 555-561. doi : 10.1016/j . i jheatmasstransfer . 2013.12.061.

[7] P. Tatsidjodoung, N. Le Pierrès, J. Heintz, D. Lagre, L. Luo, F. Durier, Experimental and numerical investigations of a zeolite $13 \mathrm{X} /$ water reactor for solar heat storage in buildings, Energy Conversion and Management 108 (2016) 488-500. doi : 10.1016/j .enconman .2015.11.011.
[8] L. Yong, K. Sumathy, Review of mathematical investigation on the closed adsorption heat pump and cooling systems, Renewable \& Sustainable Energy Reviews 6 (4) (2002) 305-337. doi:10.1016/S1364-0321(02) 00010-2.

[9] G. G. Ilis, M. Mobedi, S. Ülkü, Comparison of Uniform and Non-uniform Pressure Approaches Used to Analyze an Adsorption Process in a Closed Type Adsorbent Bed, Transport in Porous Media 98 (1) (2013) 81-101. doi: $10.1007 / \mathrm{s} 11242-013-0134-1$.

URL http://dx.doi.org/10.1007/s11242-013-0134-1

[10] B. Formisano, C. Bonten, Extruded zeolitic honeycombs for sorptive heat storage, AIP Conference Proceedings 1779 (1) (2016) 030003. doi: 10. $1063 / 1.4965473$.

[11] F. Akhtar, L. Andersson, S. Ogunwumi, N. Hedin, L. Bergström, Structuring adsorbents and catalysts by processing of porous powders, Journal of the European Ceramic Society 34 (7) (2014) 1643-1666. doi: $10.1016 / j$. jeurceramsoc. 2014.01.008.

[12] F. Rezaei, P. Webley, Structured adsorbents in gas separation processes, Separation and Purification Technology 70 (3) (2010) 243-256. doi: 10.1016/j.seppur. 2009.10.004.

[13] H. Thakkar, S. Eastman, A. Hajari, A. A. Rownaghi, J. C. Knox, F. Rezaei, 3D-Printed Zeolite Monoliths for CO2 Removal from Enclosed Environments, Acs Applied Materials \& Interfaces 8 (41) (2016) 2775327761. doi:10.1021/acsami.6b09647.

[14] J. Jaenchen, T. H. Herzog, K. Gleichmann, B. Unger, A. Brandt, G. Fischer, H. Richter, Performance of an open thermal adsorption storage system with Linde type A zeolites: Beads versus honeycombs, Microporous and Mesoporous Materials 207 (2015) 179-184. doi:10.1016/ j.micromeso.2015.01.018.

[15] H. Liu, K. Nagano, D. Sugiyama, J. Togawa, M. Nakamura, Honeycomb filters made from mesoporous composite material for an open sorption thermal energy storage system to store low-temperature industrial waste heat, International Journal of Heat and Mass Transfer 65 (2013) 471-480. doi:10.1016/j.ijheatmasstransfer.2013.06.021.

[16] C. A. Grande, S. Cavenati, P. Barcia, J. Hammer, H. G. Fritz, A. E. RODRIGUES, Adsorption of propane and propylene in zeolite 4A honeycomb monolith, Chemical Engineering Science 61 (10) (2006) 30533067. doi:10.1016/j.ces. 2005.11.058.

[17] A. Patton, B. D. Crittenden, S. P. Perera, Use of the linear driving force approximation to guide the design of monolithic adsorbents, Chemical Engineering Research \& Design 82 (A8) (2004) 999-1009. doi:10. 1205/0263876041580749.

[18] K. C. Chan, C. Y. H. Chao, G. N. Sze-To, K. S. Hui, Performance predictions for a new zeolite $13 \mathrm{X} / \mathrm{CaCl} 2$ composite adsorbent for adsorption cooling systems, International Journal of Heat and Mass Transfer 55 (1112) (2012) 3214-3224. doi:10.1016/j.ijheatmasstransfer. 2012.02 .054$.

[19] I. Solmus, D. A. S. Rees, C. Yamali, D. Baker, A two-energy equation model for dynamic heat and mass transfer in an adsorbent bed using silica gel/water pair, International Journal of Heat and Mass Transfer 55 (19-20) (2012) 5275-5288. doi:10.1016/j.ijheatmasstransfer.2012. 05.036.

[20] L. Yong, K. Sumathy, Comparison between heat transfer and heat mass transfer models for transportation process in an adsorbent bed, International Journal of Heat and Mass Transfer 47 (8-9) (2004) 1587-1598. doi:10.1016/j.ijheatmasstransfer.2003.10.025.

[21] M. Wutz, H. Adam, Theorie und Praxis der Vakuumtechnik, Vol. 64, Springer-Verlag, 2013.

[22] D. Hänel, Molekulare Gasdynamik: Einführung in die kinetische Theorie der Gase und Lattice-Boltzmann-Methoden, Springer, Berlin [u.a.], 2004.

[23] F. Sharipov, I. Graur, General approach to transient flows of rarefied gases through long capillaries, Vacuum 100 (2014) 22-25. doi:10.1016/j . vacuum. 2013.07.017.

[24] V. Vučelić, D. Vučelić, Heat capacities of water on zeolites, Studies in Surface Science and Catalysis 24 (1985) 475-480.

[25] W. Kast, Adsorption aus der Gasphase, Ingenieurwissenschaftliche Grundlagen und technische Verfahren, VCH Verlagsgesellschaft, Weinheim, Basel, Cambridge, New York, 1988. doi:10.1002/bbpc. 19900940122. URL http://dx.doi.org/10.1002/bbpc. 19900940122

[26] D. D. Do, Adsorption Analysis: Equilibria and Kinetics:(With CD Containing Computer Matlab Programs), Vol. 2, World Scientific, 1998. 
[27] T. Ewart, P. Perrier, I. Graur, J. G. Meolans, Mass flow rate measurements in gas micro flows, Experiments in Fluids 41 (3) (2006) 487-498. doi : 10.1007/s00348-006-0176-z.

[28] M. Schäfer, Computational Engineering - Introduction to Numerical Methods, Springer, Berlin Heidelberg, 2006.

[29] J. D. Lambert, Numerical methods for ordinary differential systems: the initial value problem, John Wiley \& Sons, Inc, 1991.

[30] L. F. Shampine, M. W. Reichelt, The MATLAB ODE suite, Siam Journal on Scientific Computing 18 (1) (1997) 1-22. doi:10.1137/ S1064827594276424.

[31] B. Mette, Experimentelle und numerische Untersuchungen zur Reaktionsführung thermochemischer Energiespeicher, Dissertation, University of Stuttgart (2014).

[32] G. Karniadakis, A. Beşkök, N. R. Aluru, Microflows and nanoflows: Fundamentals and simulation, Vol. v. 29 of Interdisciplinary applied mathematics, Springer, New York, NY, 2005.

\section{Appendix A. Numerical Implementation}

\section{Appendix A.1. Solving Method}

Three indicator variables are defined for the mesh study to examine the convergence of the pressure, temperature and the water uptake. For the pressure the duration of the inflowing vapour to reach the end of the channel $\left(t_{p, 10}=t\left(p(L)=p_{\text {in }} / 10\right)\right.$ is analysed. Further, the convergence of the temperature is analyses by the maximum temperature and the convergence of the water uptake by the maximal occurring difference between local water uptake and local equilibrium water uptake. The results for an initial and minimal knot spacing of $\Delta z_{\min }=$ $(L / 250, L / 500, L / 1000)$ are summarized in Tab. A.2. In addition, the relative changes of the indicator variables by reduction of the knot spacing are noted. From the relative changes it follows, that for a knot spacing of $\Delta z_{\min }=L / 500$ the solution has converged.

Table A.2: Selected results of the mesh study for two representative cases of low and high dynamics.

Case 1 (low dynamics): $p_{0}=0.001 \mathrm{mbar}, T_{0}=20^{\circ} \mathrm{C}$,

$X_{0}=0.055 \mathrm{~kg} / \mathrm{kg}, d_{\mathrm{i}}=0.5 \mathrm{~mm}, d_{\mathrm{o}}=3 d_{\mathrm{i}}\left(\varepsilon_{\mathrm{c}}=0.11\right), L=1 \mathrm{~m}$

Case 2 (high dynamics): $p_{0}=0.1 \mathrm{mbar}, T_{0}=50^{\circ} \mathrm{C}$,

$X_{0}=0.21 \mathrm{~kg} / \mathrm{kg}, d_{\mathrm{i}}=2.0 \mathrm{~mm}, d_{\mathrm{o}}=1.5 d_{\mathrm{i}}\left(\varepsilon_{\mathrm{c}}=0.44\right)$,

$L=0.01 \mathrm{~m}$

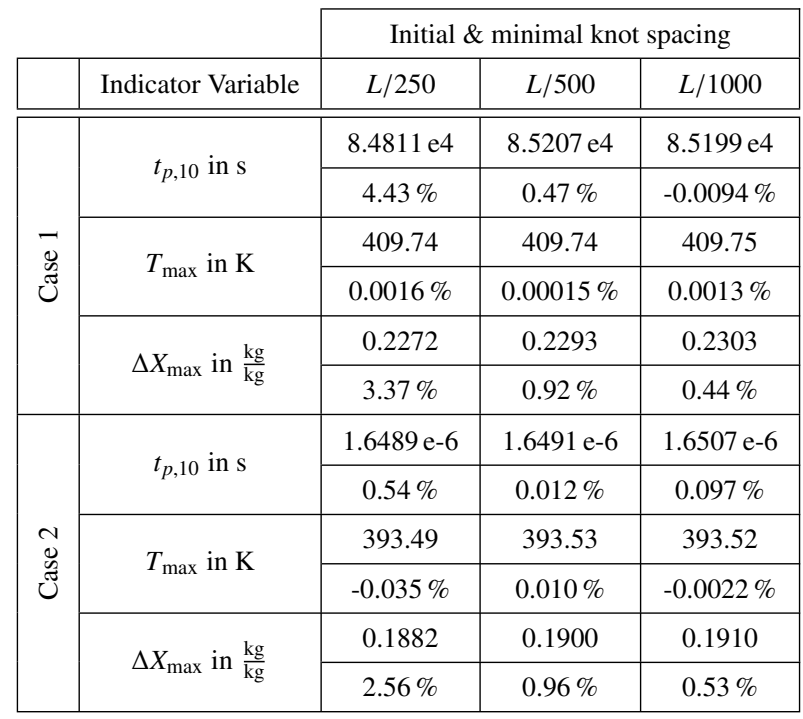

Table A.3: Implemented material parameters (mainly taken from [6, 31]).

\begin{tabular}{|c|c|c|}
\hline Parameter & Value & Unit \\
\hline$R_{\mathrm{S}}$ & 461.401 & $\frac{\mathrm{J}}{\mathrm{kg} \mathrm{K}}$ \\
\hline$\mu_{\text {ref }}$ & $1.235096 \mathrm{e}-5$ & $\frac{\mathrm{kg}}{\mathrm{ms}}$ \\
\hline$T_{\text {ref }, \mu}$ & 373.15 & $\mathrm{~K}$ \\
\hline$s$ & 1.137054 & - \\
\hline$\rho_{\mathrm{z}}$ & 1150 & $\frac{\mathrm{kg}}{\mathrm{m}^{3}}$ \\
\hline$c_{\mathrm{z}}$ & 880 & $\frac{\mathrm{J}}{\mathrm{kg} \mathrm{K}}$ \\
\hline$c_{p, \mathrm{v}}$ & 2080 & $\frac{\mathrm{J}}{\mathrm{kg} \mathrm{K}}$ \\
\hline$c_{\mathrm{a}, \min }$ & 836 & $\frac{\mathrm{J}}{\mathrm{kg} \mathrm{K}}$ \\
\hline$\alpha$ & 37.6 & $\frac{\mathrm{J}}{\mathrm{kgK}}$ \\
\hline$\beta$ & $3.976 \mathrm{e}-4$ & $\mathrm{~K}^{-2}$ \\
\hline$T_{\mathrm{ref}, c_{\mathrm{a}}}$ & 335 & $\mathrm{~K}$ \\
\hline$T_{\min }$ & 210 & $\mathrm{~K}$ \\
\hline$\varepsilon_{\max }$ & 0.6 & - \\
\hline$\lambda_{\mathrm{z}}$ & 0.4 & $\frac{\mathrm{w}}{\mathrm{mK}}$ \\
\hline$\lambda_{\mathrm{a}}$ & 0.5562 & $\frac{\mathrm{W}}{\mathrm{mK}}$ \\
\hline$\lambda_{\mathrm{v}}$ & 0.025 & $\frac{\mathrm{w}}{\mathrm{mK}}$ \\
\hline$d_{\mathrm{mp}}$ & 300 e- 9 & $\mathrm{~m}$ \\
\hline$\tau$ & 4 & - \\
\hline$v_{\mathrm{a}, \max }$ & $341.03 \mathrm{e}-6$ & $\frac{\mathrm{m}^{3}}{\mathrm{~kg}}$ \\
\hline$E$ & $1.19225 \mathrm{e} 6$ & $\frac{\mathrm{J}}{\mathrm{kg}}$ \\
\hline$n$ & 1.55 & - \\
\hline$\rho_{\mathrm{a}, 20^{\circ} \mathrm{C}}$ & 996 & $\frac{\mathrm{kg}}{\mathrm{m}^{3}}$ \\
\hline$\beta$ & $0.21 \mathrm{e}-3$ & $\mathrm{~K}^{-1}$ \\
\hline$\Delta h_{\mathrm{e}}$ & $2.6 \mathrm{e} 6$ & $\frac{\mathrm{J}}{\mathrm{kg}}$ \\
\hline
\end{tabular}

